\title{
A multi-decadal hindcast of a physical-biogeochemical model and derived oceanographic indices in the Bay of Biscay
}

\author{
Martin Huret $^{\mathrm{a}, *}$, Marc Sourisseau ${ }^{c}$, Pierre Petitgas $^{b}$, Caroline Struski $^{\mathrm{b}}$, Fabien Léger $^{\mathrm{d}}$, Pascal Lazure ${ }^{\mathrm{c}}$ \\ a Ifremer, STH/LBH, B.P. 7029280 Plouzané, France \\ ${ }^{b}$ Ifremer, EMH, rue de l'île d'Yeu, BP 21105, 44311 Nantes Cedex 03, France \\ c Ifremer, Département DYNECO, B.P. 7029280 Plouzané, France \\ d LEGOS/OMP, 14, Av. Edouard Belin, 31400 Toulouse, France \\ *: Corresponding author : Martin Huret, Tel.: +33 298224136 ; fax: +33 229008547 ; \\ email address : martin.huret@ifremer.fr
}

\begin{abstract}
:
Multiple year oceanographic simulations (hindcast) are identified as a priority oceanography product for fisheries and environment studies since they provide a unique continuous long-term dataset allowing integrated assessment of the ocean state and evolution. We performed a 37 year (19722008) hindcast run with a coupled physical-biogeochemical model in the Bay of Biscay. The coupled model and the hindcast configuration are described. A model skill assessment is performed with a large set of in-situ data. Average seasonal currents show major circulation patterns over the shelf. Among tracers, temperature and salinity have the best agreement, ahead of nitrates and silicates, chlorophyll, and finally phosphates and ammonium. For chlorophyll, improved pattern statistics are found when compared to monthly composites of satellite-derived chlorophyll data. From the hindcast, we derived indices related to mesoscale activity (eddies, plumes, fronts, stratification) and production (chlorophyll and primary production). They help characterise the evolution of the environment in a functional way, on both the seasonal and multi-decadal scales. From these indices, first, a multivariate analysis reveals an increasing number of years that deviate from the mean seasonal pattern. Second, we propose interpretations of the simulated increasing trends detected in several of them (temperature, thermocline depth and primary production). We also recommend further developments to confirm these simulated evolutions, from addition of open boundary forcing with a global circulation model, to the improvement of the dynamics of nutrient regeneration and of the seasonal variability of secondary production. As a perspective, we review the different applications made from our hindcast in relation to anchovy life cycle, a species of major interest in the Bay of Biscay.
\end{abstract}

Keywords: Physical-biogeochemical model ; Hindcast ; Skill assessment ; Environmental indices ; Seasonal pattern ; Interannual variability ; Fisheries oceanography ; Bay of Biscay 


\section{Introduction}

There is a growing interest in continuously monitoring the ocean environment, from surface to bottom and over several decades from past to future, with the need to understand and anticipate its implication in global change. Among other needs, a reference state of the marine environment is required by the Marine Strategy Framework Directive (Anonymous, 2008), as well as the assessment of the impact of the ocean evolution on marine resources and fisheries (Cury et al., 2008).

Satellite remotely sensed data has already shown its potential in deriving ecosystem indicators (Chassot et al., 2011), however temporal coverage is historically limited to launch of earth observation satellites (end of the eighties) and spatial coverage is limited to the ocean surface layers. Coupled physical-biological models provide an extensive source of information on both the physical and biological state of the ocean in three dimensions. Limitations on the duration of model simulations decrease while computing power increases, the main remaining constraint being then external forcing conditions (atmospheric or river discharges). Also, an extensive list of oceanographic or ecosystem indices may be derived from these models (e.g. Planque et al., 2006; Crosnier et al., 2008). The indices are useful to explicit mesoscale physical structures that are implicit in the model outputs of the state variables, and relate those to primary production and higher trophic levels.

Multi-decadal hindcast using hydrodynamic model have been run recently and assessed on their ability to simulate both seasonal and interannual variability (e.g. Meyer et al., 2011; Vidal-Vijande et al., 2011). Also coupled physical-biogeochemical models have been developed and used for two decades, and are now ready for hindcast simulations: see two products available at www.wgoofe.org for the North Sea based on the ECOSMO (Schrum et al., 2006) and NORWECOM (Hjollo et al., 2009) models. In this paper, we present the hindcast of a physical-biogeochemical model (ECOMARS) run 
for the Bay of Biscay over a 37 years period (1972-2008). The model is a N3-P3-Z2-D3 type model, and was used to simulate the dynamics of pico-nanoplankton, diatoms and dinoflagellates, under the limitations of nitrogen, silicates and phosphates, and of microand meso-zooplankton. The model is constrained by realistic meteorological forcing as well as daily river run-off and loads. As both the physical and biogeochemical models were primarily developed to study the shelf dynamics (Lazure and Dumas, 2008; Loyer, 2001), this paper also focuses on the continental shelf area.

The oceanography of the Bay of Biscay is not forced by one major driver and is best characterised by a variety of mesoscale features being active according to climatic and seasonal conditions (Puillat et al., 2004) which inevitably affects fish populations (Koutsikopoulos and Le Cann, 1996). Typically, mesoscale structures range from tens to a few hundred kilometres and last from a few weeks to months. Mesoscale structures are highly energetic and are often associated with areas of strong biological activity under the Bakun's fundamental triad (Bakun, 1996) processes (enrichment, retention and concentration). Consequently, in addition to model state variables, we derived a suite of indices describing the depth and strength of stratification, location of fronts, eddies and upwellings, and extension of river plumes. Biological production is provided through the vertically integrated primary production. As a whole, the hindcast provides half of the variables listed as useful by the ICES Working Group on Operational Oceanographic Products for Fisheries and Environment (WGOOFE) and among them, the eight most requested variables by the ICES community (Berx et al., 2011).

The present paper objectives are (i) to present the coupled model and hindcast configuration, (ii) to provide a general skill assessment of the model results, (iii) to introduce the derived oceanographic indices, and (iv) to give an integrated view of the system at the seasonal and multi-decadal scale based on these indices. A validation step has already been assessed on physical variables (Lazure et al., 2009). Here we complete it over a longer time-series, but we emphasize the assessment of biological variables, 
using in-situ available data over the whole time-series and ocean-colour satellite data from 1998. The model and some of its derived indices has already shown its potential for defining a spatial typology of the hydrological structures of the bay (Planque et al, 2006) or for statistical monitoring of the environment (Woillez et al., 2010), taking into account deviance from reference spatial patterns based on EOF analysis. Here, leaving apart the spatial patterns, we focus on the temporal evolution benefiting from the long time series available. This allows the characterisation of the seasonal pattern using Multiple Factor Analysis (MFA), and the description of the major environment trends observed in the last decades. Our paper finally highlights perspective uses of such a product for fisheries oceanography studies and discusses areas of further development in order to improve such modelling exercises.

\section{The coupled model and hindcast simulation}

\subsection{The hydrodynamic model}

The hydrodynamic component of our coupled model is MARS (hydrodynamic Model for Application at Regional Scale, Lazure and Dumas, 2008). The model was set up over the Bay of Biscay area and validated for tide and hydrology (Lazure and Dumas, 2008; Lazure et al., 2009). The geographic domain of the 3D model extends from $43.2^{\circ} \mathrm{N}$ to $50.8^{\circ} \mathrm{N}$, and from $8^{\circ} \mathrm{W}$ to $0.4^{\circ} \mathrm{W}$, covering the whole Bay of Biscay and the entrance of the English Channel (Fig.1). It uses a $\sim 4 \mathrm{~km}$ horizontal regular grid in a polar coordinate system, with 30 sigma layers in the vertical with refinement in the surface layers. A 2D model is run over a larger area (from Portugal to Norway) to provide surface elevation to the 3D model boundaries. A total of eight tidal constituents along the open boundary of the large model were extracted from FES2004 (Lyard et al. 2006). The 3D model is run with an adaptive time-step, never exceeding $15 \mathrm{mn}$. 


\subsection{The biogeochemical model}

The model MARS is coupled to a biogeochemical model (Fig.2) describing the seasonal evolution of primary production by diatoms, dinoflagellates and pico-nanoplankton, with limitations by nitrates, ammonium, phosphates and silicates. Phosphates can be adsorbed to and desorped from Suspended Particulate Inorganic Matter (SPIM) and may be a limiting factor for production in some coastal locations during certain period of the year (Labry et al., 2002). All elements are present in the detritus under particulate matter form. We model two zooplankton compartments, microzooplankton and mesozooplankton, the latter being the closure term of our model. This model results from successive coupled model works over the Bay of Biscay (Loyer, 2001; Huret et al., 2007) or local areas within the region (Chapelle, 1994; Ménesguen et al., 2006).

All biogeochemical tracers are coupled to the hydrodynamics through the advectiondiffusion equation :

$$
\frac{\partial X}{\partial t}=-\vec{V} \cdot \nabla X+\nabla \cdot(\kappa \nabla X)+\frac{D X}{D t}
$$

with $\mathrm{X}$ the tracer, $\mathrm{V}$ the $3 \mathrm{D}$ velocity field, $\mathrm{\kappa}$ the eddy diffusivity coefficient, and $\mathrm{DX} / \mathrm{Dt}$ the source-minus-sink term representing the biological processes. Source-minus-sink equations are available in Annexe A and model state variables and parameter values in Annexe B. Light availability for primary production is limited by cloud cover, available from the meteorological forcing, and by Suspended Particulate Matter (SPM) available as a monthly climatology product based on ocean-colour data (Gohin et al., 2005) .

\subsection{The hindcast configuration}

The model is run over the period 1972-2008 with realistic meteorological and run-off forcing. Outputs are saved on a three day basis, a frequency chosen as a compromise between disk space limitations and the need for capturing short time scale events such as effects of wind events or blooms. This does not keep the high frequency variability such as the one of tidal currents, but is enough to capture mesoscale activity or bloom events. The simulation would not have been possible without the code parallelisation 
running on a cluster. Solving the model on its $213 * 148 * 30$ grid matrix takes approximately 20h for one year using 32 CPUs, so more than a month for the complete run.

Atmospheric forcing (wind fields, air temperature, atmospheric pressure, cloud cover and relative humidity) are provided by ERA (1.125 ${ }^{\circ}$ and $6 \mathrm{~h}$ resolution, Uppala et al, 2005) for the period 1971-2001 and from the Météo-France model ARPEGE $\left(0.5^{\circ}\right.$ and 6h resolution) for the period 1996-2008. Two time-series were thus created between 1996 and 2001 using the two meteorological models for correction purpose (see 2.4.7). The ARPEGE series is however the reference for the common period. Bulk formulae are used for heat fluxes calculations (Lazure et al., 2009). Daily river discharges from the Loire, Gironde, Adour and Vilaine rivers are considered. For these rivers, nutrient inputs in nitrogen, silicate and phosphate, as well as the organic part of these elements are constrained. The concentrations were calculated for every day of the time-series based on regression analysis between river run-off and scattered nutrient data following Guillaud et al. (2008). Figure 3 shows both time-series of freshwater and nutrient discharges with strong correlation between them on the annual scale.

Open boundary conditions for temperature and salinity are provided by the Reynaud climatology (Reynaud, 1998). Climatological data from the Levitus atlas (Levitus et al., 1998) provide open boundary conditions in chlorophyll-a and nutrients.

\section{Model skill assessment}

\subsection{The physical variables}

Lazure et al. (2009) assessed the physical model skills against a variety of temperature and salinity data (climatology, in-situ and SST remote-sensing). The biases and root mean square errors (RMSE) remain very weak at all depths when comparing salinity ( $<0.1$ and $<0.6$ psu, respectively). The predicted temperature shows a global 
overestimation of temperature (bias around $0.8^{\circ} \mathrm{C}$ ) and the maximum errors are located near the thermocline (rmse of $1^{\circ} \mathrm{C}$ at $20-40 \mathrm{~m}$ ). Heat fluxes and vertical mixing parametrisation are given as the main causes of discrepancy in the vertical distribution of temperature. However, the seasonal variability appeared correctly simulated as well as the dynamics of large river plumes. As a consequence of this first assessment step, the validity of the temperature and salinity provide strong support to the validity of the associated model variables and associated indices such as stratification, frontal and plume indices.

To support indices related to the circulation dynamics as introduced in section 4 , we propose here some validation of the mean circulation and its variance. Lazure and Dumas (2008) validated the high frequency tidal signal. As a detailed validation of the dynamics at different scales is beyond the scope of our paper, and because our output of velocity fields are average over three days like other variables, we only assess here the model skills at simulating the spatial patterns on the seasonal scale. For this we compare our model results to the climatology of the seasonal surface circulation and Eddy Kinetic Energy (EKE) proposed by Charria et al. (this issue) computed from a large dataset of drifters. EKE is calculated as in Charria et al. (this issue) and characterises the variance of the velocity fields within a given season. Circulation and EKE are calculated for a depth of $10 \mathrm{~m}$, so at shallower depth than in Charria et al. (this issue) who averaged drifters between 15 and 80m. However, when using only $15 \mathrm{~m}$ depth drifters, they only show few differences in their climatology, making our comparison relevant.

Figure 4 shows mean seasonal circulation over EKE for the four seasons. Over the shelf, the model simulates the reversal of the circulation from northward to southward in spring, and the opposite from summer to autumn. In autumn, strong mean currents in the range $2-5 \mathrm{~cm} \cdot \mathrm{s}^{-1}$ similar to observations occur along the coast in the north of the Bay, whereas the model seems to underestimate in the south. During the same season, the 
observed cyclonic cell in the north is well simulated. In spring, the mean circulation over the shelf is low, with the shift in direction during that season due to a shift in average wind direction and the reduction of river run-offs. In summer, circulation is accelerated along the coast, in particular in the southern part of the Bay as shown by observations. Along the Spanish coast, intense westward current occur in spring and mostly summer during which mean values are higher than $5 \mathrm{~cm} . \mathrm{s}^{-1}$. However this westward circulation remains in autumn and winter, whereas observations reveal a circulation along the slope in the opposite direction. The lack of velocity forcing at open boundaries in our version of the model does not allow the occurrence of the poleward slope current, or Navidad (Garcia-Soto et al, 2002), intrusion during the winter months, explaining this misfit along the slope, that propagates towards the French part of the continental slope.

EKE results show similar patterns as in the observations, i.e. higher values in general offshore than over the shelf, maximum values along the Spanish coast and along the northern coast of the Bay, especially during the autumn and winter months, and finally a lower average value over the Bay in summer than in winter (30\%). However, the mean annual EKE $\left(13 \mathrm{~cm}^{2} . \mathrm{s}^{-2}\right)$ is much lower than the one calculated from drifters. This may be explained by the temporal resolution of our outputs that filters out part of the variability, as well as the spatial resolution that does not allow all the circulation variability to be simulated, in particular the part related to submesoscale activity. Indeed, our 4km resolution model is not eddy-resolving nor eddy-permitting for most submesoscale eddies observed over continental shelves on scales of $\mathrm{O}(5 \mathrm{~km})$ (Capet et al., 2008; Badin et al., 2009).

\subsection{The biological variables vs. in-situ data}

The skill assessment was extended here to the biogeochemical model with focus on nutrients and chlorophyll-a. This was assessed over the whole hindcast period with restriction to the Bay of Biscay shelf area. The dataset was compiled with data extracted 
from the ICES oceanographic database (http://www.ices.dk/ocean/), with in addition data gathered from recent surveys, i.e. Modycot between 1999 and 2003 aboard RV 'La Perouse', Pelgas from 2003 aboard the RV 'La Thalassa', Microdyn in 2004 and ECLAIR in 2008 aboard RVs 'Thalia', 'Gwen-Drez', 'Côte d'Aquitaine' and 'Côte de la Manche'. Only chlorophyll-a measurements from water sampling was kept in the analysis, without consideration of fluorometer profiles. Temporal and spatial distribution of this in-situ database is shown on Figures 5 and 6, respectively. Nutrient measurements were available on the same magnitude, except ammonium which was measured in fewer occasions. Temperature (T) and salinity (S) were from CTD casts. Data is available from the late seventies for $\mathrm{T}$ and $\mathrm{S}$, and from the late eighties for nutrients and chlorophyll, with two peaks around 1990 and 2000. Seasonal distribution reflects the main occurrence of surveys in spring with a large peak around May and a smaller one in October. The spatial distribution is more evenly spread than temporal distribution, but with a larger sampling effort undertaken in the vicinity of the major river plumes. Thus the model skill assessment depends on the bias in the distribution of the dataset, with a high density in regions and season with strong variability, respectively plumes and spring. However, since no interpolation products from this dataset is available so far, we keep its original resolution for this validation step and compare with the corresponding cell grid and depth of the model.

We evaluated the different model variables with a methodology allowing for their comparative assessment. In achieving this we used the Taylor diagram (Taylor, 2001) which proposes to represent through a single point three pattern statistics : the ratio of the standard deviations of the two fields (model and data), their correlation, and their centred RMS difference. To allow for different quantity to be represented on the same diagram, both the standard deviation and RMS are normalised by the standard deviation of the observation for each variable. The diagram (Fig.7) confirms the agreement of model vs. data for temperature and salinity over a longer period than previously assessed (Lazure et al., 2009). Looking at the whole dataset (Fig.7a), correlation 
coefficient is higher than 0.9 for both variables, and their magnitude of variability is within $10 \%$ of the observed magnitude of variability. The agreement for biological variables is less, with a decreasing order of performance for NO3, Si, chlorophyll and last NH4 and PO4. This ranking generally agrees with a review of current state of mechanistic biogeochemical modelling (Arhonditsis and Brett, 2004).

One reason for higher discrepancy of the biological variables is that a biogeochemical model can only be as good as the physical framework on which it is based (Arhonditsis and Brett, 2004). And a misfit in any physical process, even if small, will inevitably affect the realism in the estimation of nutrients and eventually of the phytoplankton biomass. For instance, as pycnocline is critical for primary production under light and nutrient limitation, a slight error in the modelling of its depth will bring large errors in the model-data comparison of biological variables around its location, where gradients are large. Figure $7 \mathrm{~b}$ shows that by getting rid of these strong vertical gradients, i.e. by only assessing the model skills for a surface layer between 0 and 5 meters, we significantly improve results on temperature and nutrients, except ammonium. Another physical source of error is the excessive diapycnal mixing that may occur in presence of strong bathymetric gradients using our sigma coordinate system (Marchesiello et al., 2009). This is likely at the origin of the slightly overestimated surface nutrients in summer (not shown), in particular in the vicinity of the shelf slope.

Nitrates and silicates dynamics are correctly simulated, even if they tend to be overestimated in summer. However, simulation of phosphates shows limited skills. Its dynamics is more difficult to capture since it is not limited to assimilation and mineralisation, but it also interacts with SPIM, introduced in the model by the river input but without any sediment dynamics. As limitation of primary production by phosphates occurs in spring in the Bay of Biscay (Labry et al., 2002; Guillaud et al., 2008), this model deficiency may in part explain the relative weak correlation $(R=0.3)$ for chlorophyll. More generally modelling remineralisation processes is a difficult task, 
as illustrated by low capacity at simulating ammonium, an intermediary product in the regeneration process. An excess of remineralisation, mainly controlling the summer production, is one of the reason for overestimation of nutrients and chlorophyll during the summer after the main spring bloom. This overestimation is revealed on the annual climatology comparison of chlorophyll with satellite data (Fig.8, see next section). Finally, the spatio-temporal resolution of our model outputs (4km and 3 days, respectively) certainly does not allow to capture all the variability of the plankton dynamics observed in the in-situ data, such as patchiness and rapid dynamics of some bloom events. This may also explain part of the chlorophyll discrepancy, as well as the $\sim 33 \%$ underestimation in the magnitude of the overall model variability (Fig.7).

No similar assessment is proposed on the zooplankton compartments since no representative dataset is available over our hindcast period. However, some information is available in spring, in particular from small pelagic fishery surveys. During late spring and over the period 1998-2008, our average simulated mesozooplankton ( 250 $\left.\mathrm{mgC} / \mathrm{m}^{2}\right)$ seems underestimated when compared to what is observed ( 1880 $\mathrm{mgC} / \mathrm{m}^{2}$ from Irigoien et al., 2009 as well as unpublished data from Pelgas surveys, after conversions considering an homogeneous maximum sampling depth of $100 \mathrm{~m}$ ), whereas microzooplankton (1160 mgC/m²) seems overestimated based on values $\left(119 \mathrm{mgC} / \mathrm{m}^{2}\right)$ found by Marquis et al. (2007). This is difficult to draw any conclusion from these few available data. Indeed, first because they are only representative of a post spring bloom situation, certainly the most dynamic and thus variable period of the year. Second, because field data make a clear size distinction between both zooplankton compartments (at $\sim 200 \mu \mathrm{m}$ ), whereas model formulations represent a trade-off between distinction by size, taxonomy (protozoa vs. metazoa) and trophic ecology. Thus size separation in the model may reveal arbitrary. When aggregated over both compartments, the estimated relative error is reduced to $\sim 25 \%$, meaning we estimate a correct overall zooplankton biomass. However, this raw comparison may still reveal a weakness of the model in simulating large biomass of mesozooplankton, that may also 
explain the excess of chlorophyll in late spring and summer, and can potentially unbalance the primary production between pico-nanoplankton and larger compartments. More generally, like in most current biogeochemical models in which the higher the trophic level, the greater is the discrepancy with the data (Arhonditsis and Brett, 2004; Radach and Moll, 2006), we expect our model to have lower skills in accurately simulating this closure term.

\subsection{The biological variables vs. satellite data}

As we do not expect the model to simulate the patchiness nor the high temporal variability of chlorophyll as observed in in-situ data, we completed our model skill assessment with satellite-derived chlorophyll data. Indeed, when averaged over the same time and space resolution as our model, this dataset provides a more synoptic view of spatial patterns for the surface in coherence with what our model should simulate. The satellite dataset is made of monthly composites over the period 1998-2008, from SeaWiFS and MODIS $1 \mathrm{~km}$ images processed with a specific algorithm for Case-2 waters (Gohin et al., 2005), and spatially averaged to fit the model grid.

Figure 8 compares the annual average spatial pattern of surface chlorophyll-a. The model (Fig.8a) is able to simulate the general spatial pattern of observed surface chlorophyll (Fig.8b) with a cross-shore gradient and maximum values in the river plumes. However, it generally overestimates the phytoplankton biomass ( 35\% over the whole shelf), in particular along the Spanish coast and at the entrance of the English Channel, except at the river mouths where the model production seems excessively light-limited in the presence of high SPIM concentrations. Then, we represent on Figure 9 the pattern statistics from every model/data grid point in a Taylor diagram, for several time-scales: every month of the 11 years, the monthly climatology, all 11 years seasonally averaged, and the annual climatology (same as Figure 8). The correlation coefficient ranges from 0.4 for every months to 0.7 for the annual climatology, a result 
similar to what was obtained in the Mid Atlantic Bight by Fennel et al. (2006). As anticipated, these coefficient values are higher than the correlation with in-situ data, since we are here comparing on better suited time and space scales. However, the normalised standard deviations are now greater than 1, revealing a general overestimation of the magnitude of the model total variability at the seasonal and annual scales. This overestimation, highest when including the seasonal pattern in the analysis, is mainly due to an overestimation of the magnitude in the seasonal signal. On both month and annual scales, the correlation is higher when comparing the climatologies than when comparing all month and/or all years. This reveals the difficulty of the model to capture all the observed interannual variability.

\section{The derived indices}

From the outputs of the state model variables, we derived 2D maps of relevant hydrological indices to further characterise the physical and biological environment (Table 1 and detailed below). They are calculated on the same spatial and temporal (3 day averages) resolution as the model outputs. The maximum depth considered when calculating depth-integrated values or when measuring gradients in the vertical dimension is $60 \mathrm{~m}$, except for the depth-integrated primary production which is integrated over the whole water column. From 2D maps of state variables and indices, we also calculated monthly and spatially integrated values of indices (see 2.4.7) to study the seasonal and interannual variability in the environment. Some of the indices are very similar and strongly correlated with each other, in particular when spatially and temporally averaged. However, this extensive list of indices is justified looking at individual maps showing some distinct patterns, potentially useful depending on the user needs.

\subsection{Stratification indices}


We follow Planque et al. (2006) and process the first index representing the necessary energy to homogenize density of the water column:

$$
\text { Def.pot }=\frac{1}{H+\xi} \int_{-H}^{\xi}\left(\bar{\rho}-\rho_{z}\right) g z d z
$$

with $\bar{\rho}$ the mean density over the water column $\bar{\rho}=\frac{1}{H+\xi} \int_{-H}^{\xi} \rho_{z} d z, \rho_{z}$ the density at depth $\mathrm{z}, H$ the bathymetry and $\xi$ the height of the free surface. So the greater the deficit, the stronger the stratification.

The density is calculated as a function of temperature and salinity, or only temperature where the focus is on temperature stratification. Figure 10a shows the mean stratification over the hindcast with respect to this index. Maximum values are located over the mid-shelf, where freshwater accumulates in spring and thermal stratification is strong in summer. Closer to shore, stratification is lowest due to tidal mixing or upwelling events.

\section{Maximum vertical gradient}

The second stratification index is the maximum vertical gradient of temperature, salinity or density. It relates to strength of stratification, but mostly helps determining the depth of the clines.

\section{Depth of thermocline, halocline and pycnocline}

The different cline depths are defined as the depths where the maximum vertical gradients are detected. It is calculated for values higher than the following thresholds, selected after sensitivity testing on the initiation of stratification : $0.15^{\circ} \mathrm{C} . \mathrm{m}^{-1}, 0.05 \mathrm{~kg} . \mathrm{m}^{-}$ ${ }^{3} \cdot \mathrm{m}^{-1}$ and $0.1 \mathrm{~m}^{-1}$ for temperature, density and salinity, respectively.

\subsection{Frontal indices}

The indices of frontal activity are based on the maximum horizontal gradient of the stratification indices. Simple horizontal gradients from surface properties could miss 
some of the fronts in the Bay of Biscay, due to subsurface occurrence without surface representation, such as around the 'Cold pool' over the northern shelf (Puillat et al., 2004), or spatial shift between surface and subsurface frontal location as is often the case in the Ushant front offshore Brittany (Le Boyer et al., 2009). Frontal indices from 2D maps of maximum vertical gradient as well as from deficit of potential energy are thus calculated.

For example, the frontal index from the maximum vertical gradient in temperature is given by:

$$
F T=\frac{1}{2} \max \left(\frac{\mid \text { Strat }_{i+1, j}-\text { Strat }_{i-1, j} \mid}{2 \mathrm{dx}}, \frac{\mid \text { Strat }_{i, j+1}-\text { Strat }_{i, j-1} \mid}{2 \mathrm{dy}}\right)
$$

with Strat one of the stratification index, and $\mathrm{dx}$ and dy the longitudinal and latitudinal resolution of the model, respectively.

Figure $10 \mathrm{~b}$ is a snapshot of the frontal index based on the maximum vertical gradient of density on May $3^{\text {th }} 1980$. Most of the frontal activity is located offshore the main rivers Loire, Gironde and Adour, bounding their plumes. The other gradients are distributed along the coast and are associated with tidal mixing or upwelling events according to local bathymetry and meteorological events. The tidal Ushant front at the tip of Britanny is a constant feature when offshore stratification is established, with its continuation into the Channel.

\subsection{Upwelling index}

This is the integration of vertical velocities $\tilde{\omega}$ in sigma coordinates over the whole

water column: Upwelling $=\sum_{0}^{n z} \tilde{\omega}$ with $\mathrm{nz}$ the number of vertical layers. Upwelling are mainly observed in southern Britanny and along the coast of 'les Landes' in the southeastern Bay of Biscay, and from spring to summer when north-westerly upwellingfavorable winds become dominant (Puillat et al., 2004). 


\subsection{River plume indices}

These indices highlight the horizontal extension of the river plumes. The first index is the surface salinity, given at a depth of $3 \mathrm{~m}$. The second index is the equivalent depth of freshwater $\delta_{f w}$ following Choi (2007):

$$
\delta_{f w}=\int_{-H}^{\xi} \frac{S_{0}-S_{z}}{S_{0}} d z \text { with } \mathrm{S}_{0} \text { a reference salinity taken as 35.5. }
$$

When the area of plume extension is calculated (see section 4.7) and averaged by year, the correlation with cumulated river discharge (Fig.3) is higher for the index based on surface salinity $(\mathrm{R}=0.82)$ than on the equivalent freshwater depth $(\mathrm{R}=0.63)$. This reveals the more conservative nature of the latter, being less affected by the vertical mixing and thus more dependent on the past months history (possibly from the previous years). The climatology made over the hindcast period (Fig.10c) reveals highest values at the river mouths and over the French mid-shelf between the Gironde and Loire estuary where freshwater accumulates.

\subsection{Eddy indices}

\section{Vorticity.}

The vorticity index measures the fluid rotation, with positive or negative values in the cyclonic, or anticyclonic direction, respectively.

$$
\omega=\frac{\partial v}{\partial x}-\frac{\partial u}{\partial y} \text { with } \mathrm{u} \text { and } \mathrm{v} \text { the horizontal components of the velocity field, } \mathrm{x} \text { and } \mathrm{y}
$$

the horizontal coordinates.

\section{Okubo-Weiss index.}

This index widely used in studies of two-dimensional turbulence (e.g. Isern-Fontanet et al., 2006) allows detection of eddy boundaries and is calculated as:

$$
\text { Okubo Weiss }=\left(\frac{\partial u}{\partial x}-\frac{\partial v}{\partial y}\right)^{2}+\left(\frac{\partial v}{\partial x}+\frac{\partial u}{\partial y}\right)^{2}-\left(\frac{\partial v}{\partial x}-\frac{\partial u}{\partial y}\right)^{2}
$$


First two terms represent the shear stress and last term the vorticity. Eddies are characterised by a strong vorticity in their center and a large shear stress deformation at their boundaries. Eddies are then detected by negative Okubo-Weiss values enclosed by positive values.

The eddy indices are calculated at a depth of $10 \mathrm{~m}$. As submesoscale eddies observed over continental shelves (Capet et al., 2008; Badin et al., 2009) are not captured by our model, only off-shelf mesoscale eddies, as well as largest shelf eddies generated from circulation interaction with topography or low salinity lenses (Puillat et al., 2004) are captured by our simulation. Figure 10d shows the map of the Okubo-Weiss index for November $8^{\text {th }}$ 2008. Most of the eddy activity is located in the vicinity of the shelf slope, in particular in the south of the bay, where they originate from slope current instabilities (Pingree and Le Cann, 1992). Over the shelf, main locations are offshore the Britanny Peninsula near the strong Ushant tidal front (Le Boyer et al., 2009), and along the coast around topography irregularities as 'Plateau de Rochebonne'.

\subsection{Biological indices}

From raw biological values, we derived the chlorophyll concentration, as the sum of chlorophyll concentrations of diatoms, dinoflagellates and pico-nanoplankton considering a Redfield C/N ratio of 6.625 and a gChl/gC ratio of 50. Surface chlorophyll-a is provided at a depth of $3 \mathrm{~m}$. The integrated primary production over the whole water column and cumulated over the output frequency is calculated for separated or aggregated phytoplankton compartments. Vertically integrated biomass of micro- and mesozooplankton are also provided. As discussed in previous section, no extensive model skills could be assessed on the separated phytoplankton and zooplankton compartments, so we did not further analyse their seasonal evolution or multiannual trend as we do in details for other variables in following sections. 
along the coast $\left(150-200 \mathrm{gC} \cdot \mathrm{m}^{-2} \cdot \mathrm{yr}^{-1}\right)$ except at the river mouths where we likely underestimate the production, in agreement with the underestimated chlorophyll (Fig.8). Variability of the annual values (Fig.11b) is highest over the French shelf in areas under the influence of river plumes, between the two main rivers Loire and Gironde, along the coast of 'Les Landes', whereas, relatively low variability is observed in the south of Brittany and along the Spanish coast. Production is also high in the Ushant front ( 130 $\mathrm{gC} \cdot \mathrm{m}^{-2} \cdot \mathrm{yr}^{-1}$ ) with relatively low variability as expected in a stable mesoscale feature.

\subsection{Integrated 1D indices}

To study the seasonal and interannual variability in the environment, we also calculated monthly averaged 1D indices from 2D maps of state variables or indices. The list of proposed 1D indices is given in Table 2. Most of them are spatially averaged values or surface areas considering threshold values. For stratified areas, the condition is that thermocline or pycnocline is established. For plume area, the threshold are 34 and 1 meter for surface salinity and equivalent freshwater depth, respectively. The OkuboWeiss area represents the surface covered by eddies, with an upper threshold of -10E-12 for the Okubo-Weiss criterion and after removal of small structures (i.e. less than 4 grid cells). The number of eddies can be directly derived from the previous index. The upwelling index is the sum of positive values of upwelling after their averaging within the $50 \mathrm{~m}$ isobath. For bloom area, the chlorophyll-a threshold value is $3 \mathrm{mg} \cdot \mathrm{m}^{-3}$.

To avoid artificial observation of differences or shift between years using ERA or ARPEGE meteorological forcing, a correction of these 1D indices over the ARPEGE period 1996-2008 was applied. The differences of ARPEGE values relatively to ERA were calculated for each index per month $\eta(I, m)$ over the years when they are both available (1996-2001), and then the following correction was applied:

$$
I_{E R A}(m)=\frac{I_{A R P}(m)}{1+\eta(I, m)} \text { with } \mathrm{I}_{\mathrm{ERA}}(\mathrm{m}) \text { the corrected value of index I for month } \mathrm{m} \text {, and }
$$

$\mathrm{I}_{\mathrm{ARP}}$ its original value. 


\section{The seasonal pattern based on the integrated indices}

We proceed with a Multiple Factor analysis (MFA), a multi-table analysis method developed to characterise the reproducibility in time of a correlation structure between variables (Escoffier and Pagès, 1994). We use it to investigate the average seasonal pattern across indices and quantify its variability between years (see Appendix C). MFA was applied on the monthly averaged $1 \mathrm{D}$ indices of section 4.7. A strong seasonal cycle is identified for the Bay of Biscay (Figs.12,13, left). In general, the interannual variability within each month is less than the inter-month variability (few overlaps between months, Fig.12, left), meaning high consistency for these periods in the reproducibility of the correlation between indices. This high consistency occurs for spring and fall months.

Some months show higher inertia than others (Fig.12,13, left) and the indices involved for these months are also more variable (Fig.12, right). February and summer months are the less variable periods across years, with the former being always well mixed and the coldest month, and the latter always strongly stratified and the warmest in surface layer. April and more generally spring is the most variable period, with plume extension being the major parameter involved in that period (Fig. 12; see also indices correlation with axis 2 in Table 3). Spring holds the start of stratification, first haline with river discharge, then thermal from May, with a large interannual variability (Puillat et al., 2004) depending on the timing of peak discharge and weather conditions (heat fluxes, wind). Fall season is also variable, though to a lesser extent (Fig.13, left), holding the deepening of stratification before its breakdown, which may be variable among years, and explains the highest temperature at bottom during this period after mixing with surface layer and before cooling through the winter.

First blooms may occur in the Bay of Biscay in late winter - early spring (e.g. Gohin et 
al., 2003), with timing and amplitude related to the variability of this season, with again the plume extension and occurrence of weather favourable windows for light availability. This can be observed for certain years from our simulation (not shown), however, major bloom extension together with highest integrated primary production seem associated to later spring during which stratification extend over the whole shelf. During summer, primary production is limited to coastal areas still under the influence of river discharge, to the subsurface chlorophyll maximum, and to frontal areas strongest in summer (Fig.12, right) such as the Ushant front showing continuous high chlorophyll concentrations (Fig.8).

Over continental shelves, eddies are expected to be associated with fronts (Badin et al., 2009), which are more intense in summer in presence of strong and deeper stratification (Fig.12). However, as submesoscale eddies are not captured with our model configuration, and also probably because tidal fronts are not so important in the Bay of Biscay except around the Ushant front, this relation does not appear in our analysis. Conversely, fronts are more associated with early spring (number of eddies) and late autumn-early winter (okubo area), which is consistent with the seasonal variability of EKE from our model (see skill assessment section and Fig.4), as well as calculated from drifters (Charria et al., this issue) and altimetry (Caballero et al., 2008). Eddies captured in our study are representative of eddies generated from slope circulation, which do not show much seasonality in the absence of open boundary forcing for currents, of low salinity lenses generating eddy activity (Puillat et al. 2004) mainly in spring, and generally of eddies originating from the interaction of circulation with topography, the former being strongest in fall and winter (Charria et al., this issue).

Summing up, the first principal axis highlights the seasonal difference between summer and winter with the indices associated to surface temperature, stratification and primary production. The second principal axis highlights the seasonal difference between spring and autumn with respect to river plumes and bottom temperature, and to a lesser extent also to upwelling and bloom activity, as well as characteristics of the eddy activity. 
The MFA also provides the distance of the years to the mean seasonal pattern (Fig.13, right). The method extracts singular years (1974, 1988, 1994, 1997 and 2006-2008) from the years close to the average pattern (1973, 1975-1976, 1979, 1989 and 1996), mostly located in the seventies. This also reveals a general increase after the early nineties of the distance to the mean seasonal pattern, meaning more chance for singular years in the recent past period.

\section{Trends in the environment}

We have selected the indices showing remarkable patterns of variability along the timeseries, as illustrated in Fig.14, and tried when data available to validate the trends in the model. Other indices are either correlated to the ones presented, or do not show any significant trend.

\subsection{Trends in the physical indices.}

Figure 14a shows the interannual variability and temporal trends of the surface temperature over the Bay of Biscay shelf. Mean surface temperature and standard deviation over the period $1973-2008$ are $15.11^{\circ} \mathrm{C}$ and $0.37^{\circ} \mathrm{C}$, respectively. 2003 is the warmest year based on the annual mean $\left(16.02^{\circ} \mathrm{C}\right)$, with 1990, 1997 and 2006 in second position. Over a larger domain extending to $12^{\circ} \mathrm{W}$, Michel et al. (2009) calculated a standard deviation of $0.44^{\circ} \mathrm{C}$ over the period $1965-2003$ from an extensive in-situ dataset Bobyclim (www.ifremer.fr/climatologie-gascogne/) and $0.41^{\circ} \mathrm{C}$ over the period 1986-2006 from a satellite SST product. The model warming trend of $0.23^{\circ} \mathrm{C} /$ decade $(\mathrm{p}<0.01)$ is also comparable to what is observed from in-situ observations $\left(0.24^{\circ} \mathrm{C} /\right.$ decade over $\left.1965-2003\right)$ and increases in the most recent decade $\left(0.30^{\circ} \mathrm{C} /\right.$ decade $)$ as observed from satellite SST $\left(0.36^{\circ} \mathrm{C} /\right.$ decade, Michel et al., 2009). Bottom temperature over the shelf (not shown) also shows a linear increasing trend but not significant. Our bottom temperature index represents different depth depending on 
the bathymetry, and thus cannot be compared to observed trend in the data at a depth of $50 \mathrm{~m}$ for example $\left(0.28^{\circ} \mathrm{C} /\right.$ decade, Michel et al., 2009).

As seen in section 4.4, plume surface is strongly correlated with cumulated river discharge. It shows a periodic oscillation (Fig.14b), with two main peaks in the early 1980s and around 2000. The interannual variability is also high and, together with the periodic oscillation, may mask the effect of the decreasing trend in the freshwater discharge over the whole time-series (see Fig.3, $-174 \mathrm{~m}^{3} . \mathrm{s}^{-1} /$ decade, $\mathrm{p}<0.05$ ).

In parallel of the surface warming, the model shows a deepening of the thermocline during summer (Fig.14c) at a rate of $1 \mathrm{~m} /$ decade $(\mathrm{p}<0.01$ ) over the northern middle shelf $\left(46^{\circ} \mathrm{N}-48^{\circ} \mathrm{N}\right)$ between the isobaths 50 and $150 \mathrm{~m}$, an area where stratification is well established. The deepening is also visible with the pycnocline, whereas the strength of the stratification, with deficit of potential energy (Fig.14d) or indices associated to maximum vertical gradients, and the stratified area index do not show any significant trend. We looked for the equivalent trend in the Bobyclim dataset (Fig.14c), after removing the bias between both time-series for easier comparison. Data is scarce in summer (see Fig.4), which may explain the higher interannual variability in the estimation of the depth of the thermocline in Bobyclim. However, we also notice a deepening trend $(1.5 \mathrm{~m} /$ decade) but not significant $(\mathrm{p}=0.12)$. In addition to the trend, we may notice a shift around 1985 in both the model and observed time-series. A completed Bobyclim dataset over the last decade, as well as a better assessment of whether higher interannual variability is artificial from the structure of the dataset, should help confirming the simulated trend.

With a hydrodynamic hindcast run in the North-Sea over the period 1948-2007, Meyer et al. (2011) could not detect any trend in the thermocline structure, neither in its intensity nor in its depth, despite a warming more intense than in the Bay of Biscay. Running a model over the Northwest European continental shelf forced by future 
scenarios of climate change, and comparing to past scenarios, Holt et al. (2010) predicted an increase of stratification strength ( $20 \%$ over the shelf including the Bay of Biscay) from the deficit of potential energy index, but without any change in the area stratified. Their first feature was not detected in our simulation, whereas their second feature is in agreement with the absence of any trend in our index of area stratified in summer, nor in our frontal indices, which in many cases delineate stratified areas. In their scenarios wind was very similar between past and forecast forcing, so warming is the only factor affecting thermocline. This may explain the difference in their estimated effect on stratification strength, although we can not exclude the effect of timescale difference (3 decades in our case, one century in Holt et al., 2010). They did not check for modification of the thermocline depth, so not comparison is possible on this index.

In addition to our hindcast run, simple scenarios of sensitivity analysis were conducted. They consisted on homogeneous increase in two of the major forcing: air temperature, wind, and a combination of both. They showed that temperature increase itself may deepen the mixed layer and increase the deficit of potential energy, as it does on the seasonal scale. The addition of wind increase contribute to the thermocline deepening when stratification is well established in summer, but counteracts the temperature effect on stratification strength. A slight increasing trend in the wind is observed from the eighties, although not statistically significant, supporting this interaction effect of temperature and wind.

\subsection{Trends in the biological indices.}

Surface chlorophyll (Fig.14e) and integrated annual primary production (Fig.14f) are proposed as biological indices. They both show high values until the early eighties, a sudden decrease in 1982, and then a slow increase until recent years. High levels of dinoflagellates production explain the high values in the seventies, both diatoms and dinoflagellates production explain the rapid decrease in 2002, while pico-nanoplankton 
does not show significant interannual variability nor trend (Fig.14f). The 2002 event may be explained by a combination of factors, among them high temperature and river discharge for that year, but we suspect some remaining influence of the initial conditions along the seventies to explain the high values of dinoflagellates over that period. Unfortunately no available data allows validation of the community structure on this timescale, nor confirmation of the productivity trend from the early eighties. The only available synoptic information is from satellite data over the period 1998-2008 (Fig14e), which is still too short to detect any trend. We observe the same bias between model and satellite time-series than the one of Figure 8, whereas the interannual variability is lower in the model than in the observation (ratio of 0.7). When compared to Figure 9, this reveals that the model overestimates the chlorophyll spatial variability whereas it underestimates the interannual variability.

The increase from the early eighties is significant for total primary productivity (4.6 gC.m ${ }^{-2} /$ decade), with major contribution from production of diatoms which also significantly increases while production of dinoflagellates and pico-nanoplankton remains stable. Over the same period surface chlorophyll concentration slightly increases but not significantly, even if it is well correlated with total primary production over the hindcast period $\left(\mathrm{R}^{2}=0.79\right)$. The scenarios that we run, described in previous section, showed that mean annual productivity decreases in the case of air temperature warming, while it increases with wind and even more in the combined scenario. This suggests that only a combination of wind increase together with the observed warming could augment the shelf productivity, in absence of any increase of river nutrient supply as confirmed on Fig.3. This observation is consistent with our hypothesis of wind increase simultaneously with surface warming to explain the deepening of thermocline. In the scenarios, surface chlorophyll was less affected than production, supporting the fact that this index shows lower increase in the last decades. This is explained by the fact that surface chlorophyll does not represent all the product of integrated primary production, and because parallel increase of model zooplankton biomass, and 
consequently increased grazing (not shown), maintains the biomass at relatively constant level. According to our model, these environmental conditions would be favourable for diatoms without any effect on other phytoplankton groups, with a likely advantage of the former under an increased mixing and availability of nutrients.

\section{Discussion}

\subsection{From simple variables to oceanographic indices}

We have illustrated the successive steps towards the elaboration of a suite of environment indicators, helpful towards the ecosystem approach to fisheries, among other applications. First with the development of a coupled model, then with its skill assessment, and finally with the derivation of a list of indicators from the hindcast simulation. The hindcast performed for the Bay of Biscay is to our knowledge the first product of this type over the region, providing the most requested variables by fisheries scientists (Berx et al., 2011), among them model raw variables such as temperature, currents, salinity, nutrients and chlorophyll, but also mesoscale features and primary productivity.

Other variables such as turbulence or bed shear-stress, and indices such as bloom timing and duration could be easily provided from such a hindcast, but were not considered consistent with our current approach in which variable or indices were averaged by month. Also dispersal or retention indices exist as described in Huret et al. (2010) but were not presented here as they were not generated over the whole hindcast period and are so far specific to the season of anchovy larval transport.

\subsection{Further developments}

Our model skill assessment classified the model variables with respect to our ability in 
simulating them correctly. Physical variables are obviously more reliable than biological ones looking at small scale patterns and high frequency processes, which is highlighted by the Taylor diagram tested on non-aggregated data. But as stated in the skill assessment section, and independently of any required improvement in the biological formulations, improvement of the physics, especially in terms of mixing, will undoubtedly lead to a better representation of the biology, in particular above the continental shelf slope. Using remote sensing data better suited for surface validation at the model scale, we showed for chlorophyll that regional spatial patterns is correctly simulated, also that best results are obtained on the annual scale, calling for further improvements of the seasonal variability, and that adding the interannual variability improves the general correlation while increasing the disagreement on the total estimated variability. Improving the seasonal variability requires a special attention to regeneration processes of nutrients, in particular phosphates with its complex dynamics and interaction with sediment. Indices related to the secondary production will require further development and validation of the zooplankton compartments. Such improvement is of primary importance if we are to connect lower to upper trophic levels through process understanding or modelling studies.

We showed that main circulation patterns (currents and EKE as seasonal climatology) were correctly simulated over the shelf. However, as altimetry products are improving over coastal areas (Dussurget et al., 2011), validation of these quantities should be assessed on a finer scale. Also model skill assessment would need to be generalised to the derived indices, such as depth of stratification with available CTD casts, eddy activity from satellite imagery (Garcia-Soto et al., 2002). As submesoscale eddies and other frontal associated processes are not well captured by our current model resolution, its increase would benefit to ecosystem modelling, especially over the shelf.

In our hindcast, inter-annual variability has only local origin, from meteorology and rivers. However another source of variability is the large scale forcing, which is not 
captured with our climatology prescription at the open boundaries for both physical and biological variables, limiting our capacity to simulate events like the Navidad in winter. As such all chaotic events are only statistically represented in our simulation and do not have any historic accuracy. The large scale forcing from Mercator physical fields is now used in the operational version of the model (www.previmer.org), and similar effort should be conducted for biological variables, especially if we are to focus not only on the shelf but rather on the whole Bay of Biscay dynamics. On the timescale of our simulation, this would require not only a multidecadal hydrodynamic model simulation at the basin scale such as the one proposed with the ORCA hindcast based on the model NEMO (Madec, 2008), but also a biogeochemical model coupled to it along this period.

\subsection{Seasonality and trends in the Bay of Biscay environment}

We used the hindcast time-series of indices to describe the seasonal variability of the Bay of Biscay environment, and the major trends observed in the last decades. To characterise the seasonal pattern of variability, we have conducted a MFA on the whole set of monthly integrated indices, providing a general view of the seasonal evolution in multiple parts of the environment, from simple physical variables to mesoscale features and primary production. Also the MFA reveals a trend towards increasing variability in the environment. Note that extreme years for one single index and a particular season, like temperature in summer 2003 (Fig.14), may in fact not be detected as singular on the seasonal scale and with this integrated view of the ecosystem. In fact, it comes out that over the recent decades there has been an increasing risk for singular years both in terms of extremes (warmest years are located in the recent past period) and seasonality (Fig.13, right). With the objective of assessing variability and detecting changes in all its components and their spatial organisation, Woillez et al. (2010) developed a statistical monitoring procedure applied to the hindcast and, already, signified an increasing number of alert for several indices (surface and bottom temperature, depth of pycnocline, coastal currents) over the last two decades. 
Over the hindcast period, the model simulated several significant trends, with a surface temperature increase accelerated from the mid-eighties, but also a deepening of the thermocline from the mid-eighties, occurring in parallel with an increase in primary production. Surface warming is well established (Gomez-Gesteira et al., 2008; Michel et al., 2009) and allowed validation of the simulated trend by our model. This is not the case for depth of stratification and primary production which are more difficult to validate with the existing set of data. However, the Bobyclim dataset shows somewhat similar patterns of evolution over the three decades, and there is general agreement that warming will change the stratification patterns on the global (Brander, 2010) and more regional scales (Holt et al., 2010). The primary production evolution is even more uncertain, and estimations vary between regions (Brander, 2010). Our simulated trend seems contradictory with respect to the anticipated decrease at mid-latitude under the effect of increased stratification strength. However, in coastal areas this decrease could be lower than in the open ocean (Holt et al. 2010), and even reversed by change in salinity or wind forcing. Slight wind increase together with warming seems to be the reason for an increase primary production in our model. Wind evolution towards the end of the century is still largely unknown, although the expectation is on an increase in average and extreme wind speeds over northern Europe (IPCC, 2007). Improvement of the model validity on the interannual scale, together with more realistic boundary forcing, is necessary to allow better assessment of the simulated trend, as well as the study of the effect of large scale climatic patterns such as the NAO (North Atlantic Oscillation) or the EA (East Atlantic Pattern), likely to downscale into the Bay of Biscay ecosystem (Borja et al., 2008).

In our analysis, we have not considered the spatial patterns of variations associated with the seasonal or long-term patterns. A MFA was applied by Petitgas et al. (2009) on a reduced number of indices from the hindcast, but on their EOF amplitudes and thus, considering their spatial patterns of variability. They show that it can be helpful in detecting local events like, for example, observed early winter blooms in the offshore 
part of the plumes (e.g. Gohin et al., 2003) which otherwise disappear in the spatially averaging procedure we have applied.

\subsection{Perspectives for fisheries oceanography}

Petitgas et al. (2009) showed that the schedules of fish life cycles correspond to specific timings within the environment seasonal pattern, with for example anchovy larval development coinciding with low variability in the environment. Thus a monitoring procedure to rapidly detect deviations from a typical seasonal pattern based on a modelling system (Woillez et al., 2010) shows promising applications in the context of the Ecosystem Approach to Fisheries. Specifically the hindcast maps can be used to derive fish habitats (Planque et al. 2007) from statistical regression of eggs or adult field distribution on environment covariates. And the hindcast integrated 1D indices, when averaged over appropriate areas and periods of the year in relation to the fish life cycles, can be used in an attempt to explain the recruitment time-series (Borja et al., 2008; Planque et al., 2008).

Ecosystem modelling is progressively moving towards end-to-end modelling, in which physical-biogeochemical models form the forcing conditions or are coupled to higher trophic level models (Travers et al, 2007; Fennel, 2008). In a first step towards a real coupling, Struski et al. (2009) used the hindcast of the Bay of Biscay to force a bioenergetics adult anchovy growth and reproduction model, providing some reasoning for the variability in the spawning season and duration. These spawning characteristics form the initial conditions for Individual Based Models (IBMs) of larval transport and survival which may also be constrained by lower trophic level models.

\section{Acknowledgements}

This study was carried out with support from the European Commission through the 
projects RECLAIM ("Resolving Climate Impact on fish stocks", FP6 - Contract 044133), UNCOVER ("Understanding the mechanisms of stock recovery", FP6 Contract 022717) and REPROdUCE of the ERA-NET MARIFISH (Contract ERAC(CT-2006-025989) and ANR. We are extremely grateful to V. Garnier for her maintenance of the MARS code, to F. Dumas and A. Ménesguen for their continuous development and maintenance of the physical and biological models, respectively. We acknowledge J. Massé for the organisation of the last decade of Pelgas surveys, C. Dupuis (University of La Rochelle) for providing chlorophyll and nutrient data from most recent surveys, F. Gohin for providing the ocean-colour satellite data, and F. Jourdin (SHOM) for providing the Modycot and OPTIC data. We also thank two anonymous reviewers for constructive comments, as well as Heidi Pethybridge for her english edition, on an earlier version of the manuscript.

\section{References}

Anonymous. 2008. Directive 2008/56/EC Marine Strategy Framework Directive. Official Journal of the European Union, L164/19.

Arhonditsis, G.B. and Brett, M.T., 2004. Evaluation of the current state of mechanistic aquatic biogeochemical modeling. Marine Ecology Progress Series, 271, 13-26.

Badin, G., Williams, R.G., Holt, J.T. and J. Fernand, L.J. 2009. Are mesoscale eddies in shelf seas formed by baroclinic instability of tidal fronts?, Journal of Geophysical Research, 114, C10021, doi:10.1029/2009JC005340

Bakun, A., 1996. Patterns in the Ocean. Ocean processes and Marine Population Dynamics, San Diego, CA, USA: University of California Sea Grant, in cooperation with Centro de Investigaciones Biologicas de Noroeste La Paz, Baja California Sur, Mexico, 323pp.

Berx, B., Dickey-Collas, M., Skogen, M.D., De Roeck, Y.-H., Klein, H., Barciela Fernandez, 
R., Foster, R., Gorringe, P., Vinay, G., Brostrøm, G., Dombrowsky, E., Huret, M., Legrand, E., Payne, M., Sagarminaga, Y., Schrum, C., Svendsen E., 2011. Does operational oceanography address the needs of fisheries and applied environmental scientists? Oceanography, 24:1, 166-171.

Borja, A., Fontan, A., Saenz, J. and Valencia V. 2008. Climate, oceanography, and recruitment: the case of the Bay of Biscay anchovy (Engraulis encrasicolus). Fisheries Oceanography. 17:6, 477-493

Brander, K. 2010. Impacts of climate change on fisheries. Journal of Marine Systems, 79, 389402

Caballero, A., Pascual, A., Dilarboure, G. and Espino, M. 2008. Sea level and Eddy Kinetic Energy variability in the Bay of Biscay, inferred from satellite altimeter data. Journal of Marine Systems, 72, 116-134.

Capet, X, Campos, I.J. and Paiva, A.M. 2008. Submesoscale activity over the Argentinian shelf. Geophysical Research Letters, 35, L15605, doi:10.1029/2008GL034736.

Chapelle, A., Lazure, P., and Menesguen A. 1994. Modelling eutrophication events in a coastal ecosystem - sensitivity analysis. Estuarine coastal and shelf science. 39(6): 529-548.

Charria, G., Lazure, P., Le Cann, B., Serpette, A., Reverdin, G., Louazel, S., Batifoulier, F., Dumas, F., Pichon, A. and Gmorel Y. Surface layer circulation derived from Lagrangian drifters in the Bay of Biscay. Journal of Marine Systems. In Revision. This issue.

Chassot, E., Bonhommeau, S., Reygondeau, G., Nieto K., Polovina, J.J., Huret, M., Dulvy, N.K., Demarcq H. Satellite remote sensing for an Ecosystem Approach to Fisheries. ICES Journal of Marine Science. 68(4): 651-666.

Choi, B.J., Wilkin, J.L. 2007. The effect of wind on the dispersal of the Hudson river plume. 
Journal of Physical Oceanography, 37: 1878-1897.

Crosnier, L. Drevillon, M., Buarque, S.R. and Soulat, F. 2008. Three ocean state indices implemented in the Mercator-Ocean operational suite. ICES Journal Of Marine Science, 65(8), 1504-1507.

Cury, P.M., Shin, Y-J., Planque, B., Durant, J.M., Fromentin, J-M., Kramer-Schadts, S., Stenseth, N.C., Travers, M., and Grimm, V. 2008. Ecosystem oceanography for global change in fisheries. Trends In Ecology Evolution, 23(6), 338-346.

Dussurget, R., Birol, F., Morrow R., and De Mey P. 2011. Fine Resolution Altimetry Data for a Regional Application in the Bay of Biscay. Marine Geodesy. 34:3-4, 447-476.

Escoffier, B. and Pagès, J., 1994. Multi factor analysis (AFMULT package). Computational Statistics and Data Analysis, 18, 121-140.

Eppley, R.W., 1972. Temperature and phytoplankton growth in the sea. Fishery Bulletin, 70(4), 1063-1085.

Fennel, K., Wilkin, J., Levin, J., Moisan, J., O'Reilly, J. and Haidvogel, D. 2006. Nitrogen cycling in the Middle Atlantic Bight: Results from a three-dimensional model and implications for the North Atlantic nitrogen budget. Global Biogeochemical Cycles, 20, GB3007, doi:10.1029/2005GB002456.

Fennel, W., 2008. Towards bridging biogeochemical and fish-production models. Journal Of Marine Systems, 71(1-2), 171-194.

Garcia-Soto, C., Pingree, R. D. and Valdés, L. 2002. Navidad development in the southern Bay of Biscay : Climate change and swoddy structure from remote sensing and in situ measurements. Journal of Geophysical Research, Vol. 107, No. C8, 10.1029/2001JC001012. 
Gohin, F. Lampert, L., Guillaud, J.F., Herbland, A., and Nézan E., 2003. Satellite and in-situ observations of a late winter phytoplankton bloom in the northern Bay of Biscay. Continental Shelf Research, 23, 1117-1141.

Gohin, F., Loyer, S., Lunven, M., Labry, C., Froidefond, J.-M., Delmas, D., Huret, M., and Herbland, A., 2005. Satellite-derived parameters for biological modelling in coastal waters: Illustration over the eastern continental shelf of the Bay of Biscay. Remote Sensing Of Environment, 95(1), 29-46.

Gomez-Gesteira, M., deCastro, M., Alvarez, I. and Gomez-Gesteira J.L. 2008. Coastal sea surface temperature warming trend along the continental part of the Atlantic Arc (19852005), J. Geophys. Res., 113, C04010, doi:10.1029/2007JC004315

Guillaud, J-F. Aminot, A., Delmas, D., Gohin, F., Lunven, M., Labry, C. and Herbland, A. 2008. Seasonal variation of riverine nutrient inputs in the northern Bay of Biscay (France), and patterns of marine phytoplankton response. Journal of Marine Systems, 72(1-4), 309-319.

Hjollo, S., Skogen, M. Svendsen, E., 2009. Exploring currents and heat within the North Sea using a numerical model. Journal of Marine Systems, 78(1), 180-192.

Holt, J., Wakelin, S., Lowe, J. and Tinker, J. 2010. The potential impacts of climate change on the hydrography of the northwest European continental shelf. Progress in Oceanography, 86, 361-379.

Huret, M., Gohin, F., Delmas, D., Lunven, M. and Garcon V. 2007. Use of SeaWiFS data for light availability and parameter estimation of a phytoplankton production model of the Bay of Biscay. Journal of Marine Systems. 65(1-4): 509-531.

Huret, M., Petitgas, P. and Woillez, M. 2010. Dispersal kernels and their drivers captured with a hydrodynamic model and spatial indices : a case study on anchovy (Engraulis 
encrasicolus) early life stages in the Bay of Biscay. Progress in Oceanography, 87, 617.

IPCC. 2007. Climate Change 2007: The physical science basis. Contribution of Working Group I to the Fourth Assessment Report of the Intergovernmental Panel on Climate Change. S. Solomon, D. Qin, M. Manning, Z. Chen, M. Marquis, K.B. Averyt, M. Tignor and H.L. Miller (Eds.). Cambridge University Press, Cambridge, U.K. pp. 996.

Irigoien, X., Fernandes, J.A., Grosjean, P., Denis, K., Albaina, A. and Santos, M. 2009. Spring zooplankton distribution in the Bay of Biscay from 1998 to 2006 in relation with anchovy recruitment. Journal of Plankton Research. 31(1), 1-17.

Isern-Fontanet, J., Garcia-Ladona, E., Font, J. 2006. Vortices of the Mediterranean Sea: An Altimetric Perspective. Journal of Physical Oceanography, 36: 87-103.

Jassby, A. and Platt, T., 1976. Mathematical formulation of relationship between photosynthesis and light for phytoplankton. Limnology and Oceanography, 21(4), 540-547.

Koutsikopoulos, C. and Le Cann, B. 1996. Physical processes and hydrological structures related to the Bay of Biscay anchovy. Scientia Marina, 60(2), 9-19.

Labry, C., Herband, A., and Delmas, D. 2002. The role of phosphorus on planktonic production of the Gironde plume waters in the Bay of Biscay. Journal of Plankton Research. 24(2), 97-117.

Lazure P., Dumas F. 2008. An external-internal mode coupling for a 3D hydrodynamical model for applications at regional scale (MARS). Advances in Water Resources. 31: 233-250.

Lazure P., Garnier V., Dumas F., Herry C., Chifflet M. 2009. Development of a hydrodynamic model of the Bay of Biscay. Validation of hydrology. Continental Shelf Research, 29: 985-997. 
Le Boyer, A., Cambon, G., Daniault, N., Herbette, S., Le Cann, B., Marié, L. and Morin, P. 2009. Observations of the Ushant tidal front in September 2007. Continental Shelf Research, 29(8), 1026-1037.

Levitus, S., Boyer, T.P., Conkright M.E., O’ Brien, T., Antonov, J., Stephens, C., Stathoplo,s L., Johnson D., Gelfeld R., 1998. NOAA Atlas NESDIS 18,World Ocean Database 1998, U. S. Gov. Printing Office, Wash., D. C., 346pp + set of Cdroms.

Loyer, S. 2001. Modélisation de la production phytoplanctonique dans la zone côtière atlantique enrichie par les apports fluviaux. Thèse de Doctorat. Université de Paris VI. 232 pp.

Lyard, F., Lefevre, F., Letellier, T. and Francis, O. 2006. Modelling the global ocean tides: modern insights from FES2004. Ocean Dynamics, 56(5-6), 394-415.

Madec, G. 2008. NEMO reference manual, ocean dynamic component: NEMO-OPA. Preliminary version, Tech. Rep. 27, Note du pôle de modélisation, Institut Pierre Simmon Laplace (IPSL), France, ISSN No 1288-1619.

Marchesiello, P., Debreu, L. and Couvelard, X. 2009. Spurious diapycnal mixing in terrainfollowing coordinate models: The problem and a solution. Ocean Modelling, 26(3-4), 156-169.

Marquis, E., Niquil, N., Delmas, D., Hartmann, H.J., Bonnet, D., Carlotti, C., Herbland, A., Labry, C., Sautour, B., Laborde, P., Vézina, A. and Dupuy C. 2007. Inverse analysis of the planktonic food web dynamics related to phytoplankton bloom development on the continental shelf of the Bay of Biscay, French coast. Estuarine, Coastal and Shelf Science, 73, 223-235.

Menesguen, A., Cugier, P., Leblond, I., 2006. A new numerical technique for tracking chemical species in a multisource, coastal ecosystem applied to nitrogen causing Ulva blooms in the Bay of Brest (france). Limnology and Oceanography, 51(1): 591-601. 
Meyer, E.M.I., Pohlmann, T. and Weisse, R., 2011. Thermodynamic variability and change in the North Sea (1948-2007) derived from a multidecadal hindcast. Journal of Marine Systems, 86(3-4), 35-44.

Michel, S., Vandermeirsch, F. and Lorance, P., 2009. Evolution of upper layer temperature in the Bay of Biscay during the last 40 years. Aquatic living resources, 22(4), 447-461.

Petitgas, P., Huret, M., Léger, F., Peck, M.A., Dickey-Collas, M. and Rijnsdorp, A.D. 2009. Patterns and schedules in hindcasted environments and fish life cycles. ICES CM 2009/E:25.

Planque, B., Lazure, P. and Jegou, A., 2006. Typology of hydrological structures modelled and observed over the Bay of Biscay shelf. Scientia Marina, 70, 43-50.

Planque, B., Bellier, E. and Lazure, P. 2007. Modelling potential spawning habitat of sardine (Sardina pilchardus) and anchovy (Engraulis encrasicolus) in the Bay of Biscay. Fisheries Oceanography, 16: 16-30.

Planque, B. and Buffaz, L. 2008. Quantile regression models for fish recruitment-environment relationships : four case studies. Marine Ecology Progress Series, 357:213-223.

Pingree, R.D. and Le Cann, B., 1992. Three anticyclonic Slope Water Oceanic eDDIES (SWODDIES) in the southern Bay of Biscay in 1990. Deep-Sea Research, 39(7/8), 1147-1175.

Puillat, I., Lazure, P., Jégou, A.-M., Lampert, L. and Miller, P.I. 2004. Hydrographical variability on the French continental shelf in the Bay of Biscay, during the 1990's. Continental Shelf Research, 24, 1143-1163.

Radach, G. and Moll, A., 2006. Review of three-dimensional ecological modelling related to the North Sea shelf system. Part II: Model validation and data needs. Oceanography And 
Reynaud, T., Le Grand, P., Mercier, H. and Barnier, B., 1998. A new analysis of hydrographic data in the Atlantic and its application to an inverse modeling study. International WOCE Newsletter, 32, 29-31.

Schrum, C., Alekseeva, I. and St John, M., 2006. Development of a coupled physical-biological ecosystem model ECOSMO - Part I: Model description and validation for the North Sea. Journal of Marine Systems, 61(1-2), 79-99.

Struski, C., Petitgas, P., and Huret, M. 2009. Long-term hindcast and climate change forecast of habitat unsuitability using bioenergetics and physical-biogeochemical models: anchovy in the Bay of Biscay and the North Sea. ICES CM 2009/E:22.

Taylor, K. 2001. Summarizing multiple aspects of model performance in a single diagram. Journal of Geophysical Research-Atmospheres, 106(D7), 7183-7192.

Travers, M., Shin, Y.J., Jennings, S. and Cury, P., 2007. Towards end-to-end models for investigating the effects of climate and fishing in marine ecosystems. Progress In Oceanography, 75(4), 751-770.

Uppala, S. et al., 2005. The ERA-40 re-analysis. Quarterly Journal of the Royal Meteorological Society, 131(612), 2961-3012.

Vidal-Vijande, E., Pascual, A., Barnier, B., Molines, J-M. and Tintoré, J. 2011. Analysis of a 44-year hindcast for the Mediterranean Sea: comparison with altimetry and in situ observations. Scientia Marina, 75(1), 71-86.

Woillez, M., Petitgas, P., Huret, M., Struski, C. and Léger, F. 2010. Statistical monitoring of spatial patterns of environmental indices for integrated ecosystem assessment, application to the Bay of Biscay pelagic zone. Progress in Oceanography. 87, 83-93. 


\section{Appendix A: Equations of the biogeochemical model}

$$
\begin{aligned}
& \frac{d \mathrm{NO}_{3}}{d t}=r n i t \times \mathrm{NH}_{4}-r_{N_{3}}^{\text {Diat }} \times \mu_{\text {Diat }} \times \text { Diat }-r_{N O_{3}}^{\text {Dino }} \times \mu_{\text {Dino }} \times \text { Dino }-r_{N_{3} O_{3}}^{N a n o} \times \mu_{N a n o} \times \text { Nano } \\
& \frac{d \mathrm{NH}_{4}}{d t}=\operatorname{rmin}_{N} \times \mathrm{N}_{\text {det }}-r_{N_{4} H_{4}}^{\text {iat }} \times \mu_{\text {Diat }} \times \text { Diat }-r_{N H_{4}}^{\text {Dino }} \times \mu_{\text {Dino }} \times \text { Dino }-r_{N H_{4}}^{N a n o} \times \mu_{N a n o} \times \text { Nano } \\
& +\frac{E_{M Z o o} \times \mathrm{MZoo}+E_{\mu z o o} \times \mu \mathrm{zoo}}{12 \times r_{C: N}^{Z o o}}-r n i t \times \mathrm{NH}_{4} \\
& \frac{d \mathrm{Si}}{d t}=\operatorname{rdis}_{S i} \times \mathrm{Si}_{\mathrm{det}}-r_{S i: N}^{P h y} \times \mu_{\text {Diat }} \times \text { Diat } \\
& \frac{d \mathrm{PO}_{4}}{d t}=k_{\text {des }} \times \text { Pads }+r \min _{P} \times \mathrm{P}_{\text {det }}+\left(E_{M Z o o} \times \mathrm{MZoo}+E_{\mu z o o} \times \mu \mathrm{zoo}\right) \times \frac{r_{P: N}^{Z o o}}{12 \times r_{C: N}^{Z o o}} \\
& -r_{P: N}^{P h y} \times\left(\mu_{\text {Diat }} \times \text { Diat }+\mu_{\text {Dino }} \times \text { Dino }+\mu_{\text {Nano }} \times \text { Nano }\right)-k_{a d s} \times \mathrm{PO}_{4} \\
& \frac{d \mathrm{Pads}}{d t}=k_{\text {ads }} \times \mathrm{PO}_{4}-k_{\text {des }} \times \mathrm{Pads} \\
& \frac{d \text { Diat }}{d t}=\left(\mu_{\text {Diat }}-m_{\text {Diat }}\right) \times \text { Diat }-g r_{\text {Diat }} \times \frac{\text { MZoo }}{12 \times r_{C: N}^{Z o o}} \\
& \frac{d \text { Dino }}{d t}=\left(\mu_{\text {Dino }}-m_{\text {Dino }}\right) \times \text { Dino }-g r_{\text {Dino }} \times \frac{\text { MZoo }}{12 \times r_{C: N}^{Z o o}} \\
& \frac{d \text { Nano }}{d t}=\left(\mu_{\text {Nano }}-m_{\text {Nano }}\right) \times \text { Nano }-g r_{\text {Nano }} \times \frac{\mu \text { zoo }}{12 \times r_{C: N}^{Z o o}} \\
& \frac{d \mathrm{MZoo}}{d t}=\left(\tau_{M} \times \mu_{M Z o o}-E_{M Z o o}-m_{M Z o o}\right) \times \mathrm{MZoo} \\
& \frac{d \mu \mathrm{zoo}}{d t}=\left(\tau_{\mu} \times \mu_{\mu z o o}-E_{\mu z o o}-m_{\mu z o o}\right) \times \mu \mathrm{zoo}-g r_{\mu z o o} \times \text { MZoo } \\
& \frac{d \mathrm{~N}_{\text {det }}}{d t}=m_{\text {Diat }} \times \text { Diat }+m_{\text {Dino }} \times \text { Dino }+m_{N a n o} \times \text { Nano }-\operatorname{rmin}_{N} \times \mathrm{N}_{\text {det }}+\frac{1}{12 \times r_{C: N}^{Z o o}} \\
& \times\left[\left(m_{M Z o o}+\left(1-\tau_{M}\right) \times \mu_{M Z o o}\right) \times \mathrm{MZoo}+\left(m_{\mu z o o}+\left(1-\tau_{\mu}\right) \times \mu_{\mu z o o}-g r_{D e t}\right) \times \mu \mathrm{zoo}\right] \\
& \frac{d \mathrm{Si}_{\mathrm{det}}}{d t}=r_{S i: N}^{P h y} \times m_{\text {Diat }} \times \mathrm{Diat}-r d i s_{S i} \times \mathrm{Si}_{\mathrm{det}}+g r_{\text {Diat }} \times \frac{\mathrm{MZoo}}{12} \times \frac{r_{S i: N}^{P h y}}{r_{C: N}^{Z o o}} \\
& \frac{d \mathrm{P}_{\text {det }}}{d t}=r_{P: N}^{P h y} \times\left(m_{\text {Diat }} \times \text { Diat }+m_{\text {Dino }} \times \text { Dino }+m_{\text {Nano }} \times \text { Nano }\right)-r m_{P} \times \mathrm{P}_{\text {det }}+\frac{r_{P: N}^{P h y}}{12 \times r_{C: N}^{Z o o}} \\
& \times\left[\left(m_{M Z o o}+\left(1-\tau_{M}\right) \times \mu_{M Z o o}\right) \times \mathrm{MZoo}+\left(m_{\mu z o o}+\left(1-\tau_{\mu}\right) \times \mu_{\mu z o o}-g r_{D e t}\right) \times \mu \mathrm{zoo}\right]
\end{aligned}
$$

Temperature limitation for most processes follows Eppley (1972): $f_{T}=\exp ^{(\mathrm{a} . \mathrm{T})}$ with $\mathrm{a}=0.07$.

\section{Primary production}

The growth rate of phytoplankton variables depends on the specific maximum phytoplankton growth rates as a function of temperature $\mathrm{f}_{\mathrm{T}}$, limited by light and 
nutrients availability :

$$
\mu=\mu^{0} \cdot f_{T} \cdot f_{\ln }
$$

with $\mathrm{f}_{\text {ln }}=\min \left(\mathrm{f}_{\text {light }}, \mathrm{f}_{\mathrm{N}}, \mathrm{f}_{\mathrm{Si}}, \mathrm{f}_{\mathrm{P}}\right)$ for diatoms and $\mathrm{f}_{\text {ln }}=\min \left(\mathrm{f}_{\text {light }}, \mathrm{f}_{\mathrm{N}}, \mathrm{f}_{\mathrm{P}}\right)$ for dinoflagellates and pico-Nanoplankton.

The light limitation $\mathrm{f}_{\text {light }}$ is given by the Smith equation (Jassby and platt, 1976).

Generally nutrient limitation follows a Michaelis-Menten function as:

$$
f_{N u}=\frac{N u}{N u+K_{N u}}
$$

For nitrogen: $\quad f_{N}=\frac{\mathrm{NO}_{3} / \mathrm{K}_{\mathrm{NO}_{3}}+\mathrm{NH}_{4} / \mathrm{K}_{\mathrm{NH}_{4}}}{1+\mathrm{NO}_{3} / \mathrm{K}_{\mathrm{NO}_{3}}+\mathrm{NH}_{4} / \mathrm{K}_{\mathrm{NH}_{4}}}$

Then the fractions of each nitrogen nutrients assimilated during primary production (see source-minus-sink equations) are given by $\mathrm{r}_{\mathrm{NH} 4}=\mathrm{f}_{\mathrm{NH} 4} / \mathrm{f}_{\mathrm{N}}$ and $\mathrm{r}_{\mathrm{NH} 4}=\mathrm{f}_{\mathrm{NH} 4} / \mathrm{f}_{\mathrm{N}}$

The phytoplankton mortality is only dependent on temperature : $\quad m=m^{0} \times f_{T}$

\section{Zooplankton}

The grazing of zooplankton is

$$
\mu_{\mathrm{Zoo}}=\mu_{\mathrm{Zoo}}^{0} \times f_{T} \times f_{\text {food }}
$$

with $\mathrm{f}_{\text {phy }}$ following an Ivlev formulation for mesozooplankton:

$$
f_{\text {food }}=1-\exp \left(-y \times \max \left(0, p_{\text {Diat }} \times \text { Diat }+p_{\text {Dino }} \times \text { Dino }+\frac{p_{\mu} \text { zoo } \times \mu \text { zoo }}{12 \times r_{C}: N}-P_{0}\right)\right)
$$

and a Michaelis-Menten formulation for microzoplankton:

$$
f_{\text {food }}=\frac{p_{\text {Nano }} \times \text { Nano }+p_{\text {Det }} \times \text { Det }}{K_{\mu \text { zoo }}+\left(\text { pNano } \times \text { Nano }+p_{\text {Det }} \times \text { Det }\right)}
$$


with $\mathrm{p}_{\text {Diat, }}, \mathrm{p}_{\text {Dino, }} \mathrm{p}_{\mu z о o}$ and $\mathrm{p}_{\text {Det }}$ preferency coefficients for diatoms, dinoflagellates, piconanoplankton and detritus.

The grazing of mesozooplankton on phytoplankton group $\mathrm{X}$ is then:

$$
g r_{X}=\frac{\mu_{M z o o} \times p_{X} \times X}{p_{\text {Diat }} \times \text { Diat }+p_{\text {Dino }} \times \text { Dino }+\frac{p_{\mu \text { zoo }} \times \mu \text { zoo }}{12 \times r_{C: N}}}
$$

and of microzooplankton on pico-nanohytoplankton or Detritus:

$$
\begin{aligned}
& g r_{X}=\frac{\mu_{\mu z o o} \times p_{X} \times X}{p_{\text {Nano }} \times N a n o+p_{\text {Det }} \times \text { Det }} \\
& \tau_{M}=0.3 \times\left(3-0.67 \times f_{p h y}\right) \quad \text { is the assimilation coefficient. }
\end{aligned}
$$

Mortality of mesozooplankton is a function of a maximum specific rate, temperature and biomass:

$$
m_{M Z o o}=f_{T} \times \max \left(m_{M Z o o}^{0}, m_{M Z o o / B i o m} \times M Z o o\right)
$$

whereas it is only dependent on temperature for microzooplankton.

Excretion is then given by: $E_{\text {Zoo }}=E_{\text {Zoo }}^{0} \times f_{T} \times f_{\text {phy }}$

\section{Mineralisation}

The mineralisation and nitrification are function of specific rates and temperature : $\operatorname{rmin}_{X}=\operatorname{rmin}^{0}{ }_{x} \cdot f_{T}$ with $X=N, P$ or $S i$, and rnit $=$ rnit $^{0} . \mathrm{f}_{T}$. 
The sinking rate of diatoms depends on the cell stress:

$W_{\text {Diat }}=W_{\min } \times f_{N u}+W_{\max } \times\left(1-f_{N u}\right) \quad$ with $\mathrm{f}_{\mathrm{Nu}}$ the limitation by nutrients.

The sinking rate of particulate organic matter depends on its origin:

$$
W_{D e t}=W_{D e t}^{z o o} \times\left(\frac{1}{r+1}\right)+W_{D e t}^{p h y} \times\left(1-\frac{1}{r+1}\right)
$$

with $\quad r=\frac{m_{\text {Diat }} \times \text { Diat }+m_{\text {Dino }} \times \text { Dino }}{\left((1-\tau) \times \mu_{\text {Zoo }}+m_{\text {Zoo }}\right) \times \text { Zoo }}$

\section{Adsorption-Desorption of phosphate}

The adsoprtion of phosphate on Suspended Particulate Inorganic Matter is given by:

$$
k_{a d s}=C_{a d s} \times \max \left(0, k_{a d s}^{\max } \times S P I M-P_{a d s}\right)
$$

The desorption coefficient is: $k_{a d s}=C_{d e s} \times \min \left(1, \frac{P_{a d s}}{k_{a d s}^{\max } \times S P I M}\right)$

\section{Appendix B.}

\begin{tabular}{|c|c|c|}
\hline Name in equations & Description & Units \\
\hline Diat & Diatoms & $\left(\mathrm{mmol} \mathrm{N} . \mathrm{m}^{-3}\right)$ \\
\hline Dino & Dinoflagellates & $\left(\mathrm{mmol} \mathrm{N} . \mathrm{m}^{-3}\right)$ \\
\hline Nano & Pico-nanoplancton & $\left(\mathrm{mmol} \mathrm{N} . \mathrm{m}^{-3}\right)$ \\
\hline Mezo & Mesozooplancton & $\left(\mathrm{mg} \mathrm{C.m} \mathrm{m}^{-3}\right)$ \\
\hline$\mu \mathrm{zoO}$ & Microzooplancton & $\left(\mathrm{mg} \mathrm{C.m} \mathrm{m}^{-3}\right)$ \\
\hline $\mathrm{NO}_{3}$ & Dissolved nitrate & $\left(\mathrm{mmol} \mathrm{N} . \mathrm{m}^{-3}\right)$ \\
\hline $\mathrm{Si}$ & Dissolved silicate & $\left(\mathrm{mmol} \mathrm{Si} \cdot \mathrm{m}^{-3}\right)$ \\
\hline $\mathrm{NH}_{4}$ & Dissolved ammonium & $\left(\mathrm{mmol} \mathrm{N} . \mathrm{m}^{-3}\right)$ \\
\hline $\mathrm{PO}_{4}$ & Dissolved phosphate & $\left(\mathrm{mmol}\right.$ P.m $\left.\mathrm{m}^{-3}\right)$ \\
\hline $\mathrm{P}_{\mathrm{ads}}$ & Adsorbed phosphate & $\left(\mathrm{mmol} \mathrm{P.m} \mathrm{m}^{-3}\right)$ \\
\hline $\mathrm{N}_{\text {det }}$ & Dissolved nitrate & $\left(\mathrm{mmol} \mathrm{N} . \mathrm{m}^{-3}\right)$ \\
\hline $\mathrm{Si}_{\text {det }}$ & Dissolved silicate & $\left(\mathrm{mmol} \mathrm{Si} . \mathrm{m}^{-3}\right)$ \\
\hline $\mathrm{P}_{\mathrm{det}}$ & Particulate phosphate & $\left(\mathrm{mmol}\right.$ P.m $\left.\mathrm{m}^{-3}\right)$ \\
\hline
\end{tabular}

Table 1. List of the biogeochemical model variables 
Table 2. List of the biogeochemical model parameters

\begin{tabular}{|c|c|c|c|}
\hline Parameter & Definition & Value & Units \\
\hline \multicolumn{4}{|l|}{ Phytoplankton } \\
\hline$r_{S i: N}^{P h y}$ & Silicon/Nitrogen ratio & 0.75 & mol.mol ${ }^{-1}$ \\
\hline$r_{N: P}^{P h y}=r_{N: P}^{Z o o}$ & Nitrogen/Phosphorus ratio & 16 & mol.mol $^{-1}$ \\
\hline$r_{C: N}^{P h y}$ & Carbon/Nitrogen ratio & 6.625 & mol.mol $^{-1}$ \\
\hline$r_{C h l: N}$ & Chlorophyll/Nitrogen ratio & 1.59 & g.Chl.(molN) $)^{-1}$ \\
\hline \multicolumn{4}{|l|}{ Diatoms } \\
\hline$\mu_{\text {Diat }}^{0}$ & Specific growth rate at $0^{\circ} \mathrm{C}$ & 0.6 & day $^{-1}$ \\
\hline$m_{\text {Diat }}^{0}$ & Specific mortality rate at $0^{\circ} \mathrm{C}$ & 0.05 & day $^{-1}$ \\
\hline$K_{N O 3}^{\text {Diat }}$ & Nitrate half-saturation & 2 & $\mu \mathrm{molN} . \mathrm{I}^{-1}$ \\
\hline$K_{N H 4}^{\text {Diat }}$ & Ammonium half-saturation & 1,5 & $\mu$ molN. $^{-1}$ \\
\hline$K_{S i}^{\text {Diat }}$ & Silicate half-saturation & 1 & $\mu$ molSi.l $^{-1}$ \\
\hline$K_{P}^{\text {Diat }}$ & Phosphate half-saturation & 0.15 & $\mu \mathrm{molP} . \mathrm{l}^{-1}$ \\
\hline $\mathrm{I}_{\mathrm{opt}}$ & Smith light flux & 50 & W.m $\mathrm{m}^{-2}$ \\
\hline \multicolumn{4}{|c|}{ Dinoflagellates } \\
\hline$\mu_{\text {Dino }}^{0}$ & Specific growth rate at $0^{\circ} \mathrm{C}$ & 0.3 & day $^{-1}$ \\
\hline$m_{\text {Dino }}^{0}$ & Specific mortality rate at $0^{\circ} \mathrm{C}$ & 0.04 & day $^{-1}$ \\
\hline$K_{N O 3}^{\text {Dino }}$ & Nitrate half-saturation & 3.8 & $\mu{\mathrm{molN} . \mathrm{l}^{-1}}^{-1}$ \\
\hline$K_{N H 4}^{\text {Dino }}$ & Ammonium half-saturation & 0.9 & $\mu{\mathrm{molN} . \mathrm{l}^{-1}}^{-1}$ \\
\hline$K_{P}^{\text {Dino }}$ & Phosphate half-saturation & 0.08 & $\mu \mathrm{molP} . \mathrm{l}^{-1}$ \\
\hline $\mathrm{I}_{\mathrm{opt}}$ & Smith light flux & 60 & W.m $\mathrm{m}^{-2}$ \\
\hline \multicolumn{4}{|c|}{ Pico-nanoplankton } \\
\hline$\mu_{\text {Nano }}^{0}$ & Specific growth rate at $0^{\circ} \mathrm{C}$ & 0.8 & day $^{-1}$ \\
\hline$m_{\text {Nano }}^{0}$ & Specific mortality rate at $0^{\circ} \mathrm{C}$ & 0.18 & day $^{-1}$ \\
\hline$K_{N O 3}^{\text {Nano }}$ & Nitrate half-saturation & 0.1 & $\mu \mathrm{molN}^{-1} \mathrm{I}^{-1}$ \\
\hline$K_{N H 4}^{\text {Nano }}$ & Ammonium half-saturation & 0.05 & $\mu$ molN.l $^{-1}$ \\
\hline$K_{P}^{\text {Nano }}$ & Phosphate half-saturation & 0.05 & $\mu \mathrm{molP} . \mathrm{I}^{-1}$ \\
\hline $\mathrm{I}_{\mathrm{opt}}$ & Smith light flux & 70 & W.m $\mathrm{m}^{-2}$ \\
\hline \multicolumn{4}{|l|}{ Zooplankton } \\
\hline$r_{C: N}^{Z o o}$ & Carbon/Nitrogen ratio & 5.45 & mol.mol ${ }^{-1}$ \\
\hline \multicolumn{4}{|c|}{ Mesozooplankton } \\
\hline$\mu_{\text {Meso }}^{0}$ & Specific growth rate at $0^{\circ} \mathrm{C}$ & 0.3 & day $^{-1}$ \\
\hline$m_{\text {Meso }}^{0}$ & Specific mortality rate at $0^{\circ} \mathrm{C}$ & 0.03 & day $^{-1}$ \\
\hline$m_{\text {Meso/Biom }}$ & Biomass-dependent mortality & 0.0006 & day $^{-1} \cdot\left(\mu \mathrm{gC}^{-1} \cdot \mathrm{l}\right)$ \\
\hline$E_{\text {Meso }}^{0}$ & Specific excretion rate & 0.03 & day $^{-1}$ \\
\hline $\mathrm{y}$ & Ivlev coefficient & 0.15 & l. $\mu \mathrm{molN}^{-1}$ \\
\hline $\mathrm{P}_{0}$ & Predation escape rate & 0.5 & $\mu \mathrm{molN}^{-1} \mathrm{I}^{-1}$ \\
\hline $\mathrm{p}_{\text {Diat }}$ & Preferency coef. for diatoms & 1 & s.u. \\
\hline $\mathrm{p}_{\text {Dini }}$ & Preferency coef. for dinoflagellates & 0.1 & s.u. \\
\hline $\mathrm{P}_{\mu z o o}$ & Preferency coef. for microzooplankton & 0.7 & s.u. \\
\hline \multicolumn{4}{|c|}{ Microzooplankton } \\
\hline$\mu_{\mu z o o}^{0}$ & Specific growth rate at $0^{\circ} \mathrm{C}$ & 0.3 & day $^{-1}$ \\
\hline$m_{\mu z o o}^{0}$ & Specific mortality rate at $0^{\circ} \mathrm{C}$ & 0.02 & day $^{-1}$ \\
\hline$K_{\mu z \text { zoo }}$ & Half-saturation for food & 0.5 & $\mu \mathrm{molN} . \mathrm{l}^{-1}$ \\
\hline$E_{\mu z o o}^{0}$ & Specific excretion rate at $0^{\circ} \mathrm{C}$ & 0.1 & day $^{-1}$ \\
\hline $\mathrm{p}_{\text {Nano }}$ & Pref. coef. for pico-nanoplankton & 1 & s.u. \\
\hline $\mathrm{P}_{\text {Det }}$ & Pref. coef. for detritus & 0.8 & s.u. \\
\hline
\end{tabular}




\begin{tabular}{|c|c|c|c|}
\hline Sinking rates & & & \\
\hline $\mathrm{W}_{\min }$ & Minimum sinking rate for Diatoms & 0.00001 & $\mathrm{~m} \cdot \mathrm{s}^{-1}$ \\
\hline $\mathrm{W}_{\max }$ & Maximum sinking rate for Diatoms & 0.00003 & $\mathrm{~m} \cdot \mathrm{s}^{-1}$ \\
\hline$W_{D e t}^{\text {Phy }}$ & Sinking rate of phytoplankton detritus & 0.00005 & $\mathrm{~m} \cdot \mathrm{s}^{-1}$ \\
\hline$W_{\text {Det }}^{\text {Zoo }}$ & Sinking rate of zooplankton detritus & 0.0014 & $\mathrm{~m} \cdot \mathrm{s}^{-1}$ \\
\hline \multicolumn{4}{|c|}{ Mineralisation rate } \\
\hline $\operatorname{rmin}_{N}$ & Specific mineralisation rate for $\mathrm{N}$ at $0^{\circ} \mathrm{C}$ & 0.02 & day $^{-1}$ \\
\hline $\operatorname{rmin}_{\mathrm{Si}}$ & Specific mineralisation rate for $\mathrm{Si}$ at $0^{\circ} \mathrm{C}$ & 0.005 & day $^{-1}$ \\
\hline $\operatorname{rmin}_{\mathrm{P}}$ & Specific mineralisation rate for $\mathrm{P}$ at $0^{\circ} \mathrm{C}$ & 0.15 & day $^{-1}$ \\
\hline rnit & Specific nitrification rate at $0^{\circ} \mathrm{C}$ & 0.02 & day $^{-1}$ \\
\hline \multicolumn{4}{|l|}{ Adsorption } \\
\hline$\overline{C_{\text {ads }}}$ & P adsorption coefficient on SPM & 0.12 & l. $\mu \mathrm{molP}^{-1}$.day $^{-1}$ \\
\hline $\mathrm{C}_{\mathrm{des}}$ & P desorption coefficient & 2.4 & day $^{-1}$ \\
\hline$k_{a d s}^{\max }$ & Max. capacity of SPM adsorption & 40 & $\mu \mathrm{molP} . \mathrm{g}^{-1}$ \\
\hline
\end{tabular}

\section{Appendix C.}

Multiple Factor analysis (MFA) is a multi-table analysis method used to characterise the reproducibility in time of a correlation structure between variables. It was processed here using the library ade4 in $\mathrm{R}$ (http://pbil.univ-lyon1.fr/ade4/). We used it to investigate the average seasonal pattern across indices and quantify its variability between years. MFA was applied on the monthly averaged 1D indices of section 4.7.

MFA proceeds as a two-step PCA. First, a PCA is applied to each yearly matrix (centre normed indices in column and months in row), and each column is standardized by the first eigen value. This step scales the yearly matrices so that all have a similar weight in the next step.

Then a PCA is performed on an overall matrix obtained by appending all the yearly matrices column by column (ny*nv columns, with ny the number of years and nv the number of $1 \mathrm{D}$ indices). The MFA results in constructing a factorial space $(\mathrm{X}, \mathrm{Y}, \ldots)$, from the overall space of all 1D indices, common to all yearly matrices in which all months, years and indices are represented. Here we only keep the first two principal axes as they explain $84.3 \%$ of the overall variability (Fig.12), and each individual $m_{i, j}$ representing one month of one year can then be decomposed as follows: 
$m_{i, j}(X, Y)=\left(x_{i, j}, y_{i, j}\right)$ with $i=[1,2, \ldots 12]$ and $j=[1,2, . . n y]$

with $\mathrm{X}_{i, j}$ the coordinate of the individual for month $\mathrm{i}$ and year $\mathrm{j}$ on the first principal axis $\mathrm{X}$ of the PCA.

The mean individual for each month is the centre of gravity between years for this month, represented by the centre of the ellipse on Fig.12, left, and given by :

$$
m_{i}(X, Y)=\left(\sum_{j=1}^{n y}\left(x_{i, j}\right) / n y, \sum_{j=1}^{n y}\left(y_{i, j}\right) / n y\right)
$$

The variability or inertia among years for each month i (Fig.13, left), can be calculated as :

$$
I_{i}(X, Y)=\left(\sum_{j=1}^{n y}\left(m_{i, j}(X)-m_{i}(X)\right)^{2} / n y, \sum_{j=1}^{n y}\left(m_{i, j}(Y)-m_{i}(Y)\right)^{2} / n y\right)
$$

and the distance of each year to the mean seasonal pattern (Fig.13, right) as :

$$
D_{j}=\sum_{i=1}^{12}\left(m_{i, j}(X)-m_{i}(X)\right)^{2}+\sum_{i=1}^{12}\left(m_{i, j}(Y)-m_{i}(Y)\right)^{2}
$$

The MFA factorial space also defines the average correlation structure between indices, and the principal factors of the MFA are interpreted by the correlation of each index with the factors. The seasonal cycle is characterised in that way from all indices (Fig.12, right). 


\section{List of Tables}

Table 1. List of hydrological indices (2D) compiled from the ECO-MARS3D hindcast.

Table 2. List of 1D monthly averaged indices. Threshold are values above which grid cells are summed to calculate areas.

Table 3. Interpretation of the MFA principal components (PC). Number of years in which the correlation between each index and the PC is $>0.5$ (in absolute value). This number is in bold when more than half of the years are correlated with the PC. The sign of the correlation is given after the count. Indices in bold are those represented on Fig.12. 


\section{List of Figures}

Fig.1 Model domain with bathymetry and rivers considered for freshwater and nutrient discharges.

Fig.2. The biogeochemical model with interactions between state variables. The four main components are gathered : Nutrients (Nitrates, Ammonium, Phosphates and Silicates), Phytoplankton (Pico-nanoplankton, Diatoms and Dinoflagellates), Zooplankton (Microzooplankton and Mesozooplankton) and Detritus (particulate N, P and Si). SPIM stands for Suspended Particulate Inorganic Matter, on which Phosphates can adsorb.

Fig. 3. Observed discharges (left) and calculated nitrogen, phosphate (x10) and silicate supply (right) to the Bay of Biscay (after Guillaud et al., 2008) from the total contribution of the four main rivers (Vilaine, Loire, Gironde, Adour). Discharges are annual averages, nutrients are cumulated by year.

Fig. 4. Seasonal maps of the current (arrows, $\mathrm{cm}^{-\mathrm{s}^{-1}}$ ) and Eddy Kinetic Energy (EKE, $\mathrm{cm}^{2} . \mathrm{s}^{-2}$, greyscale color in the background) calculated from the model velocity fields at a depth of $10 \mathrm{~m}$.

Fig. 5. Annual (left) and seasonal (right) distribution of observations used for model validation. Chlorophyll and nutrients are on top panels, temperature and salinity on bottom panel.

Fig. 6. Spatial distribution of available in-situ observations over the period 1972-2008 for model skill assessment. CTD casts (left panel) and water sampling (right panel) for chlorophyll-a analysis.

Fig. 7. Taylor diagram on a set of model variables for (a) the whole water column and 
(b) for surface $(<5 \mathrm{~m})$ over the shelf area of the Bay of Biscay. Model/data comparison is made on all in-situ data available over the hindcast period (see text for details). Three pattern statistics are synthesised on the diagram: (i) the radial distance from the origin is proportional to the ratio of standard deviation between the model and data fields, (ii) the azimuthal position indicates the correlation coefficient, and (iii) the distance between the variable position and 'Obs' indicates the unbiased RMS difference. To allow for different quantities to be represented on the same diagram, both the standard deviation and RMS are normalised by the standard deviation of the observations for each variable.

Fig. 8. Annual climatology of surface chlorophyll-a (mgChl.m ${ }^{-3}$ ) from (a) the hindcast and (b) satellite data over the period 1998-2008. The satellite climatology is built from monthly composites of SeaWiFS and MODIS images. Isobaths 100, 1000, 2000 and 3000 are drawn.

Fig. 9. Taylor diagram comparing monthly of composites of chlorophyll-a from model and satellite data on different timescales over the period 1998-2008. M: All month of all 11 years; c.M: Monthly climatology; Y: All 11 years; c.M: Annual climatology. All grid points are used in the computation (i.e. 12 months x 11 years $\mathrm{x}$ number of grid points in the case of $\mathrm{M}$ ). See Fig.6 for diagram interpretation.

Fig. 10. Annual climatology of the (a) deficit of potential energy (kg. $\left.\mathrm{m}^{-1} \cdot \mathrm{s}^{-2}\right)$ and (c) equivalent depth of freshwater (m), and snapshots of (b) the frontal index (kg.m ${ }^{3} \cdot \mathrm{m}^{-2}$ ) from the maximum vertical gradient of density and of (d) the eddy index from Okubo-Weiss $\left(\mathrm{x} 10^{-12} \cdot \mathrm{s}^{-2}\right)$ criteria.

Fig. 11. Integrated annual primary production $\left(g C \cdot \mathrm{m}^{-2} \cdot \mathrm{yr}^{-1}\right)$. (a) Climatology over the hindcast period and (b) associated standard deviation, calculated from annual 
means of each year.

Fig. 12. Seasonal pattern : representation of the mean months (left) and indices (correlation circle: right) in the MFA subspace of the 2 first principal axes, representing $84,3 \%$ of the variability. Each point represents a particular year. Only selected indices of Table 3 are plotted for clarity.

Fig. 13. Variability across years: inertia for each month (left) and distance to the mean seasonal pattern for each year (right) over the Bay of Biscay shelf, as derived from the MFA.

Fig. 14. Time-series of model annual means for (a) surface temperature, (b) plume area, (c) depth of thermocline (with unbiased Bobyclim comparison, see text, dotted line), (d) deficit of potential energy, (e) surface concentration in chlorophyll (with satellite derived chlorophyll-a, dotted line) and (f) integrated primary production for all phytoplankton compartments. Indices are averaged by year over the Bay of Biscay shelf, except for stratification indices (c,d) for which it is averaged for the summer season (months 7, 8 and 9) between $46^{\circ} \mathrm{N}$ and $48^{\circ} \mathrm{N}$ and the 50 and $150 \mathrm{~m}$ isobath. Regression slope is added when significant $(\mathrm{p}<0.05)$. 


\section{Tables}

Table 1. List of hydrological indices (2D) compiled from the ECO-MARS3D hindcast.

\begin{tabular}{|c|c|}
\hline Hydrological indices & Units \\
\hline \multicolumn{2}{|l|}{ Stratification indices } \\
\hline Deficit of potential energy (density) & kg.m $\mathrm{m}^{-1} \cdot \mathrm{s}^{-2}$ \\
\hline Deficit of potential energy (temperature) & kg. $\mathrm{m}^{-1} \cdot \mathrm{s}^{-2}$ \\
\hline Maximal vertical gradient of density & $\mathrm{kg} \cdot \mathrm{m}^{-3} \cdot \mathrm{m}^{-1}$ \\
\hline Maximal vertical gradient of temperature & ${ }^{\circ} \mathrm{C} . \mathrm{m}^{-1}$ \\
\hline Depth of thermocline & $\mathrm{m}$ \\
\hline Depth of pycnocline & $\mathrm{m}$ \\
\hline Depth of halocline & $\mathrm{m}$ \\
\hline \multicolumn{2}{|l|}{ Frontal indices } \\
\hline Thermal frontal index (potential energy) & kg.m $\mathrm{m}^{-2} \cdot \mathrm{s}^{-2}$ \\
\hline Density frontal index (potential energy) & $\mathrm{kg} \cdot \mathrm{m}^{-2} \cdot \mathrm{s}^{-2}$ \\
\hline Thermal frontal index (maximal gradient) & ${ }^{\circ} \mathrm{C} . \mathrm{m}^{-2}$ \\
\hline Density frontal index (maximal gradient) & kg. $\mathrm{m}^{-3} \cdot \mathrm{m}^{-2}$ \\
\hline \multicolumn{2}{|l|}{ Upwelling indices } \\
\hline Vertical speed in $\sigma$ coordinates & $\mathrm{s}^{-1}$ \\
\hline Vertical speed in z coordinates & m.d $\mathrm{d}^{-1}$ \\
\hline \multicolumn{2}{|l|}{ River plume indices } \\
\hline Salinity at surface & psu \\
\hline Equivalent fresh water height & $\mathrm{m}$ \\
\hline \multicolumn{2}{|l|}{ Eddies indices } \\
\hline Vorticity (10m) & $\mathrm{S}^{-1}$ \\
\hline Okubo-Weiss (10m) & $\mathrm{s}^{-2}$ \\
\hline \multicolumn{2}{|l|}{ Biological indices } \\
\hline Surface chlorophyll (chla) concentration (at 3m) & mgChla.m ${ }^{-3}$ \\
\hline Integrated primary production & gC. $\mathrm{m}^{-2}$ per 3 days \\
\hline Integrated primary production (Diatoms) & gC.m ${ }^{-2}$ per 3 days \\
\hline Integrated primary production (Dinoflagellates) & gC. $\mathrm{m}^{-2}$ per 3 days \\
\hline Integrated primary production (Pico-nanoplankton) & gC.m ${ }^{-2}$ per 3 days \\
\hline Integrated microzooplankton biomass & gC.m ${ }^{-2}$ \\
\hline Integrated mesozooplankton biomass & gC.m ${ }^{-2}$ \\
\hline \multicolumn{2}{|l|}{ Other indices } \\
\hline Temperature at surface (at 3m) & ${ }^{\circ} \mathrm{C}$ \\
\hline Temperature at the bottom & ${ }^{\circ} \mathrm{C}$ \\
\hline Current U-component (W-E) at the surface (at 10m) & $\mathrm{cm} \cdot \mathrm{s}^{-1}$ \\
\hline Current V-component (S-N) at the surface (at 10m) & $\mathrm{cm} . \mathrm{s}^{-1}$ \\
\hline EKE (Eddy Kinetic Energy) at the surface (at 10m) & $\mathrm{cm}^{2} \cdot \mathrm{s}^{-2}$ \\
\hline
\end{tabular}


Table 2. List of 1D monthly averaged indices. Threshold are values above which grid cells are summed to calculate areas.

\begin{tabular}{|l|l|l|}
\hline Integrated indices & Units & Threshold value \\
\hline Surface temperature (3m) & ${ }^{\circ} \mathrm{C}$ & \\
\hline Bottom temperature & ${ }^{\circ} \mathrm{C}$ & \\
\hline Thermocline depth & $\mathrm{m}$ & \\
\hline Temperature gradient (max.) & $\mathrm{m}$ & \\
\hline Pycnocline depth & $\mathrm{m}$ & \\
\hline Deficit of potential energy & $\mathrm{kg}^{-2} \cdot \mathrm{s}^{-2}$ & \\
\hline Stratified area (thermocline) & $\mathrm{km}^{2}$ & $0.15^{\circ} \mathrm{C}_{\mathrm{m}} \mathrm{m}^{-1}$ \\
\hline Stratified area (pycnocline) & $\mathrm{km}^{2}$ & $0.05 \mathrm{~kg} \cdot \mathrm{m}^{-3} \cdot \mathrm{m}^{-1}$ \\
\hline Equivalent fresh water height & $\mathrm{m}$ & \\
\hline Plume area (surface salinity) & $\mathrm{km}^{2}$ & $34 \mathrm{psu}$ \\
\hline Plume area (equivalent fresh water height) & $\mathrm{km}^{2}$ & $1 \mathrm{~meter}$ \\
\hline Density frontal index (potential energy) & $\mathrm{kg}^{-2} \cdot \mathrm{s}^{-2}$ & \\
\hline Upwelling index & $\mathrm{s}^{-1}$ & \\
\hline Vorticity & $\mathrm{s}^{-1}$ & \\
\hline Okubo-Weiss (eddies) area & $\mathrm{km}^{2}$ & $10 \mathrm{E}-11 \mathrm{~s}^{-2}$ \\
\hline Number of eddies & & \\
\hline Surface chlorophylle concentration (at 3m) & ${\mathrm{mgChla} \cdot \mathrm{m}^{-3}}$ \\
\hline Bloom area & $\mathrm{km}^{2}$ & $3 \mathrm{mgChla} \cdot \mathrm{m}^{-3}$ \\
\hline Primary production & ${\mathrm{gC} \cdot \mathrm{m}^{-2}}$ \\
\hline
\end{tabular}


Table 3. Interpretation of the MFA principal components (PC). Number of years in which the correlation between each index and the PC is $>0.5$ (in absolute value). This number is in bold when more than half of the years are correlated with the PC. The sign of the correlation is given after the count. Indices in bold are those represented on Fig.11.

\begin{tabular}{|c|c|c|c|c|c|}
\hline Index & Definition & \multicolumn{2}{|c|}{ First axis } & \multicolumn{2}{|c|}{ Second axis } \\
\hline Temp.surf & Surface temperature (3m) & $37+$ & $0-$ & $0+$ & 0 - \\
\hline Temp.bot & Bottom temperature & $19+$ & $0-$ & $36+$ & $0-$ \\
\hline Thermo.depth & Thermocline depth & $37+$ & $0-$ & $15+$ & $0-$ \\
\hline Thermo.gdt & Temperature gradient (max.) & $36+$ & $0-$ & $0+$ & $1-$ \\
\hline Pycno.depth & Pycnocline depth & $28+$ & $0-$ & $31+$ & $0-$ \\
\hline Def.Pot.E & Deficit of potential energy & $37+$ & $0-$ & $0+$ & $0-$ \\
\hline Thermo.area & Stratified area (thermocline) & $37+$ & $0-$ & $0+$ & $0-$ \\
\hline Pycno.area & Stratified area (pycnocline) & $37+$ & $0-$ & $0+$ & $0-$ \\
\hline Fresh.depth & Equivalent depth of freshwater & $3+$ & $5-$ & $1+$ & $32-$ \\
\hline Plume.sal & Plume area (surface salinity) & $1+$ & $0-$ & $0+$ & 36- \\
\hline Plume.fresh & Plume area (equivalent fresh water height) & $1+$ & $13-$ & $0+$ & 31- \\
\hline Front & Density frontal index (from deficit of potential energy) & $37+$ & $0-$ & $0+$ & $1-$ \\
\hline Upwelling & Upwelling index & $0+$ & $0-$ & $0+$ & 29- \\
\hline Okubo.area & Okubo-Weiss (eddies) area & $0+$ & $17-$ & $32+$ & $0-$ \\
\hline Nb.eddies & Number of eddies & $0+$ & 9- & $0+$ & $35-$ \\
\hline Chla & Surface chlorophylle concentration (at 3m) & $37+$ & $0-$ & $0+$ & $10-$ \\
\hline Bloom & Bloom area & $37+$ & $0-$ & $0+$ & $18-$ \\
\hline PP & Primary production & $37+$ & $0-$ & $0+$ & $8-$ \\
\hline
\end{tabular}


Figures

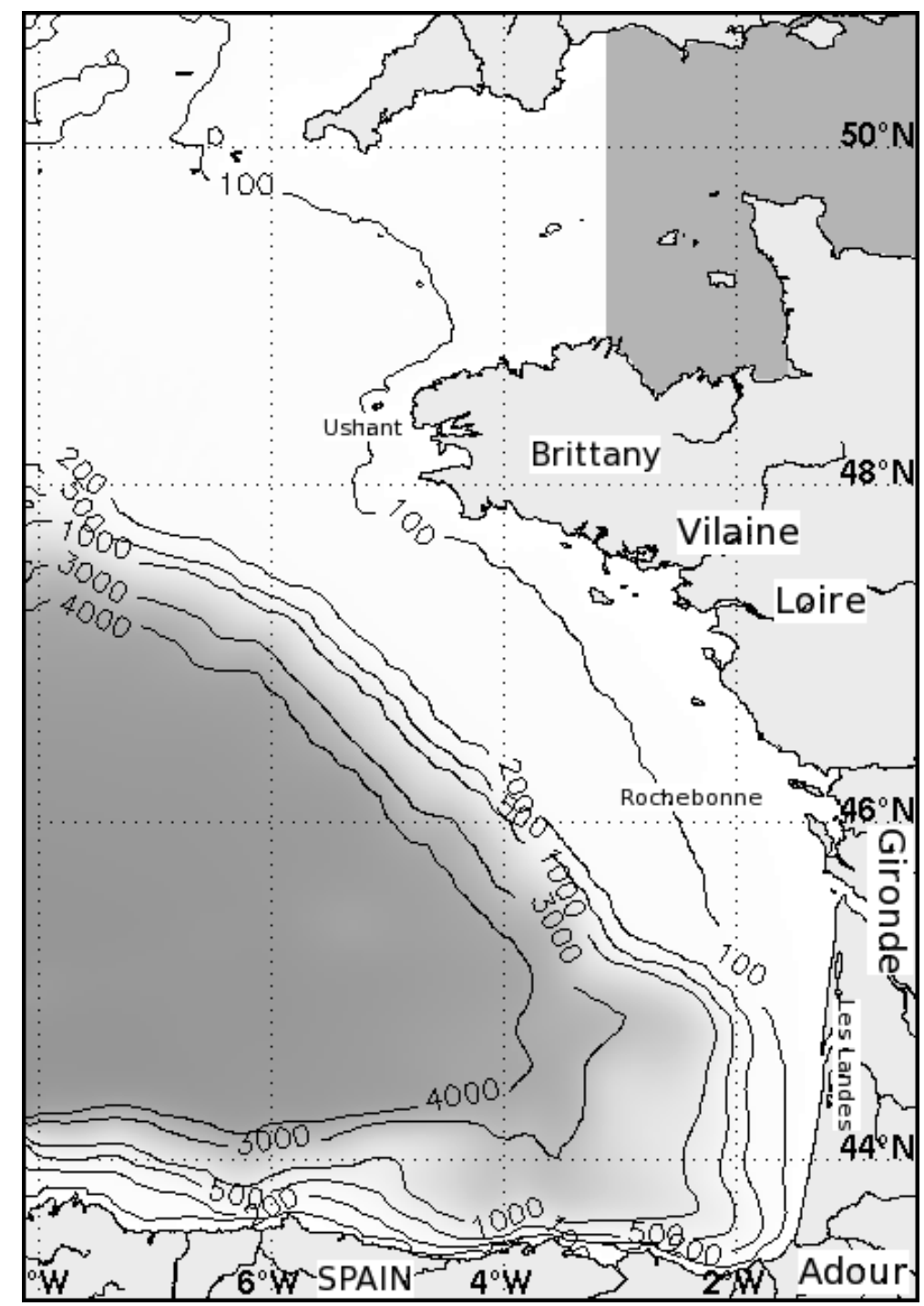

Fig.1 Model domain with bathymetry and rivers considered for freshwater and nutrient discharges. 


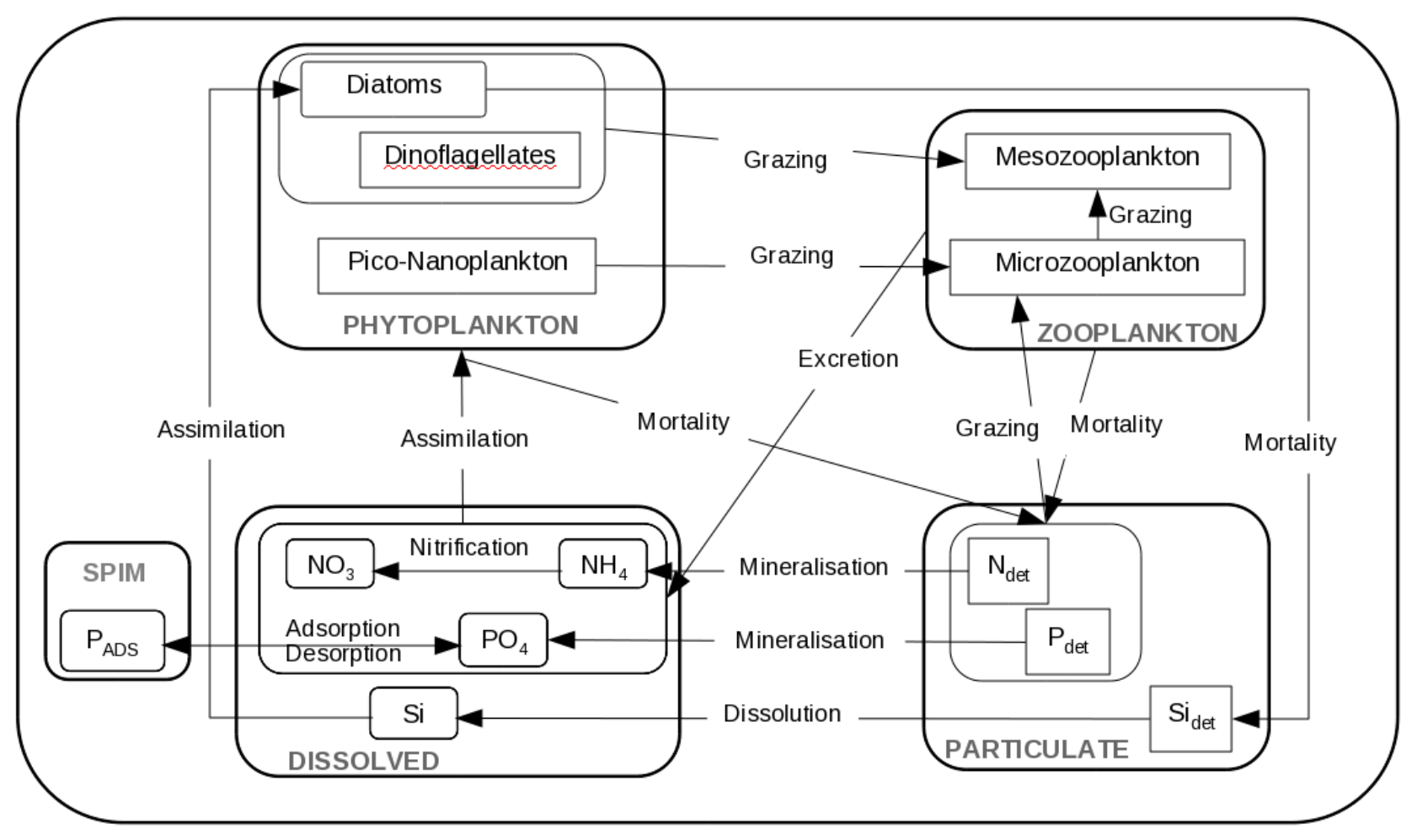

Fig.2. The biogeochemical model with interactions between state variables. The four main components are gathered : Nutrients (Nitrates, Ammonium, Phosphates and Silicates), Phytoplankton (Pico-nanoplankton, Diatoms and Dinoflagellates), Zooplankton (Microzooplankton and Mesozooplankton) and Detritus (particulate N, P and Si). SPIM stands for Suspended Particulate Inorganic Matter, on which Phosphates can adsorb. 

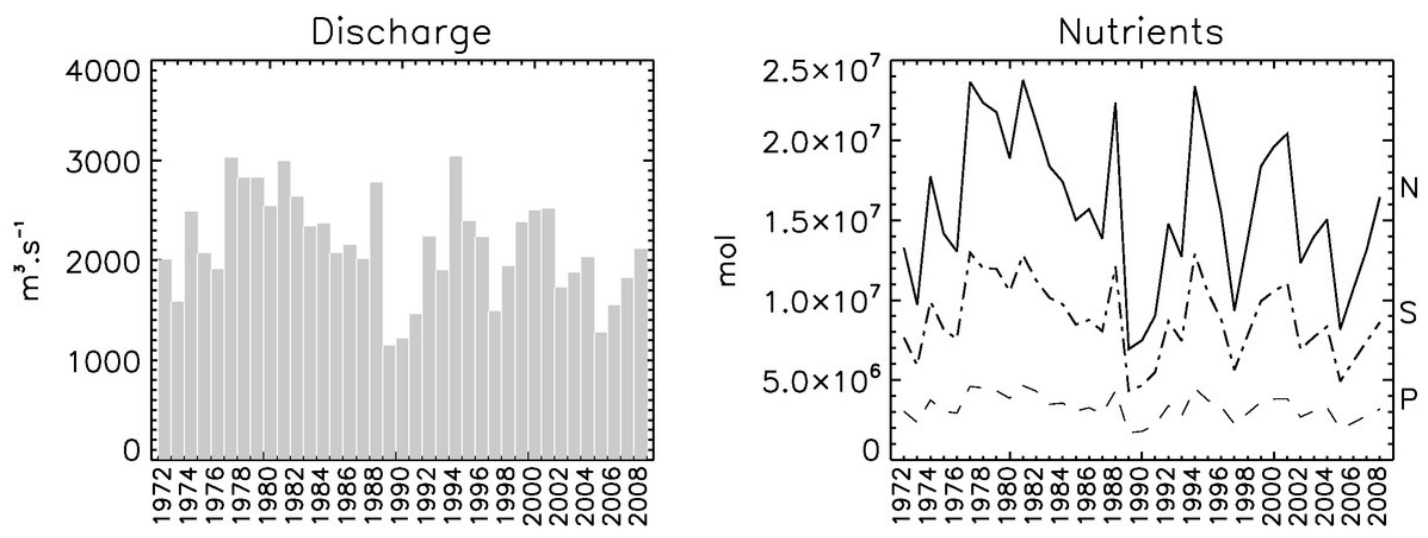

Fig. 3. Observed discharges (left) and calculated nitrogen, phosphate (x10) and silicate supply (right) to the Bay of Biscay (after Guillaud et al., 2008) from the total contribution of the four main rivers (Vilaine, Loire, Gironde, Adour). Discharges are annual averages, nutrients are cumulated by year. 
(a) OCT-NOV-DEC

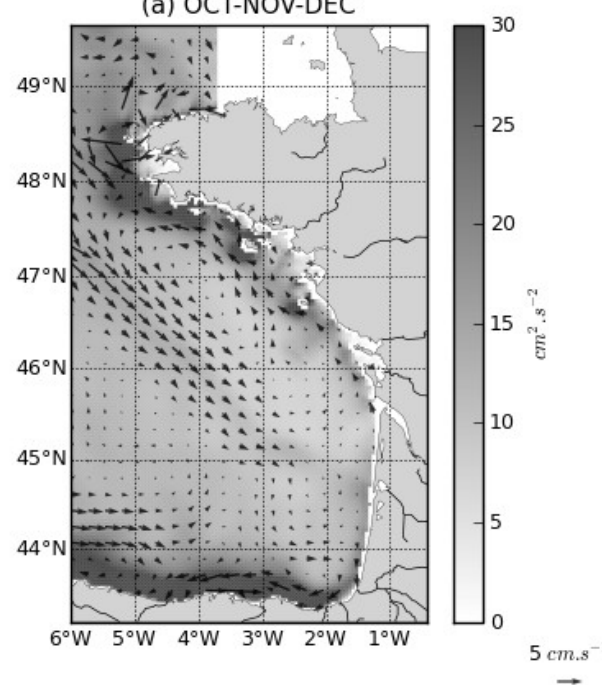

(c) APR-MAY-JUN

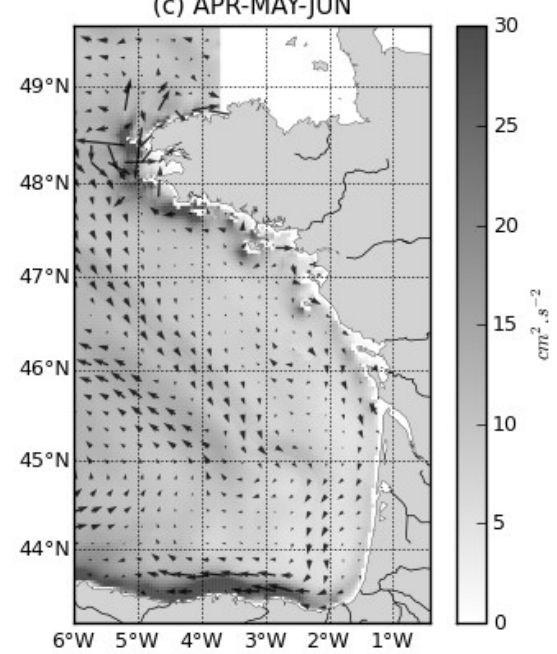

(b) JAN-FEB-MAR

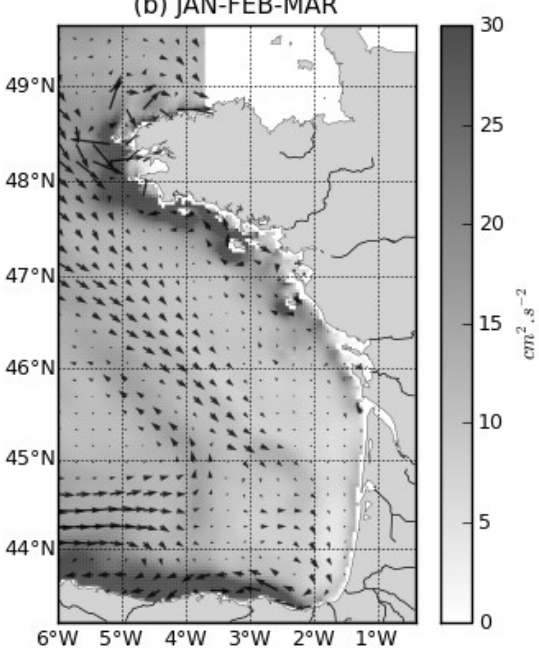

(d) JUL-AUG-SEP

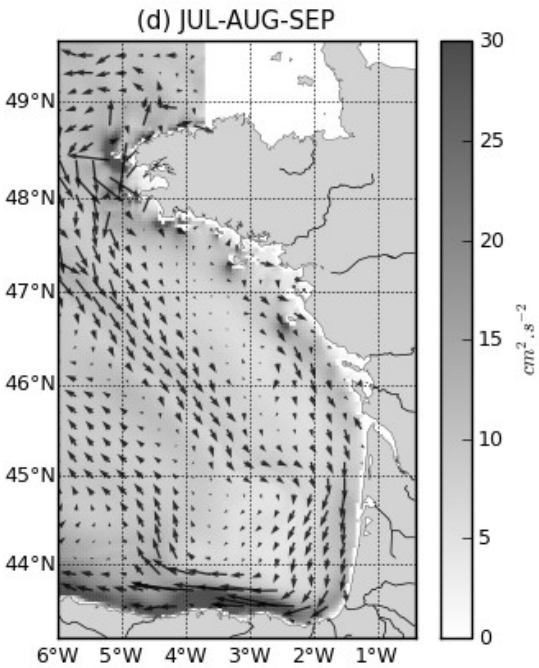

Fig. 4. Seasonal maps of the current (arrows, $\mathrm{cm} \cdot \mathrm{s}^{-1}$ ) and Eddy Kinetic Energy (EKE, $\mathrm{cm}^{2} \cdot \mathrm{s}^{-2}$, greyscale color in the background) calculated from the model velocity fields at a depth of $10 \mathrm{~m}$. 

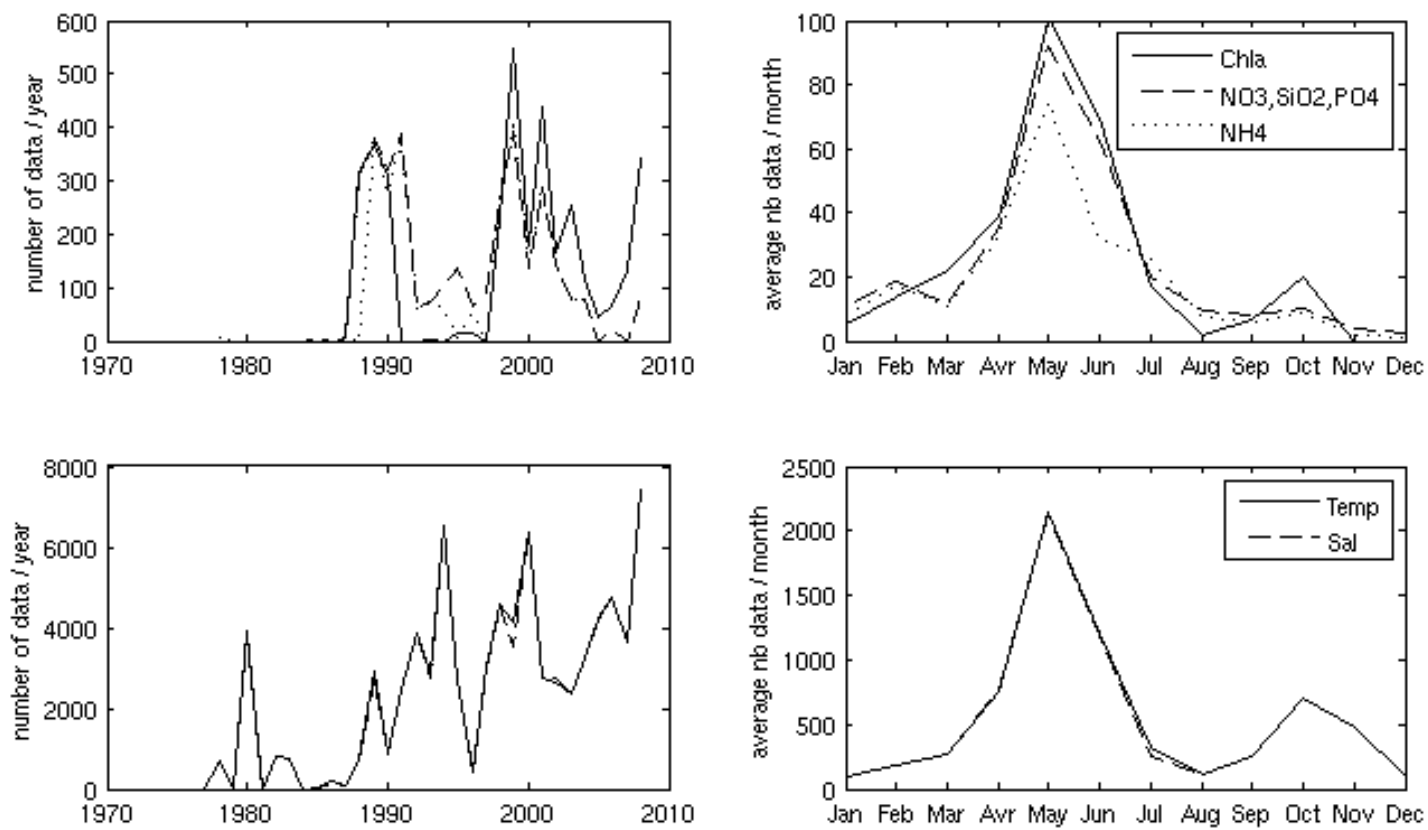

Fig. 5. Annual (left) and seasonal (right) distribution of observations used for model validation. Chlorophyll and nutrients are on top panels, temperature and salinity on bottom panel. 

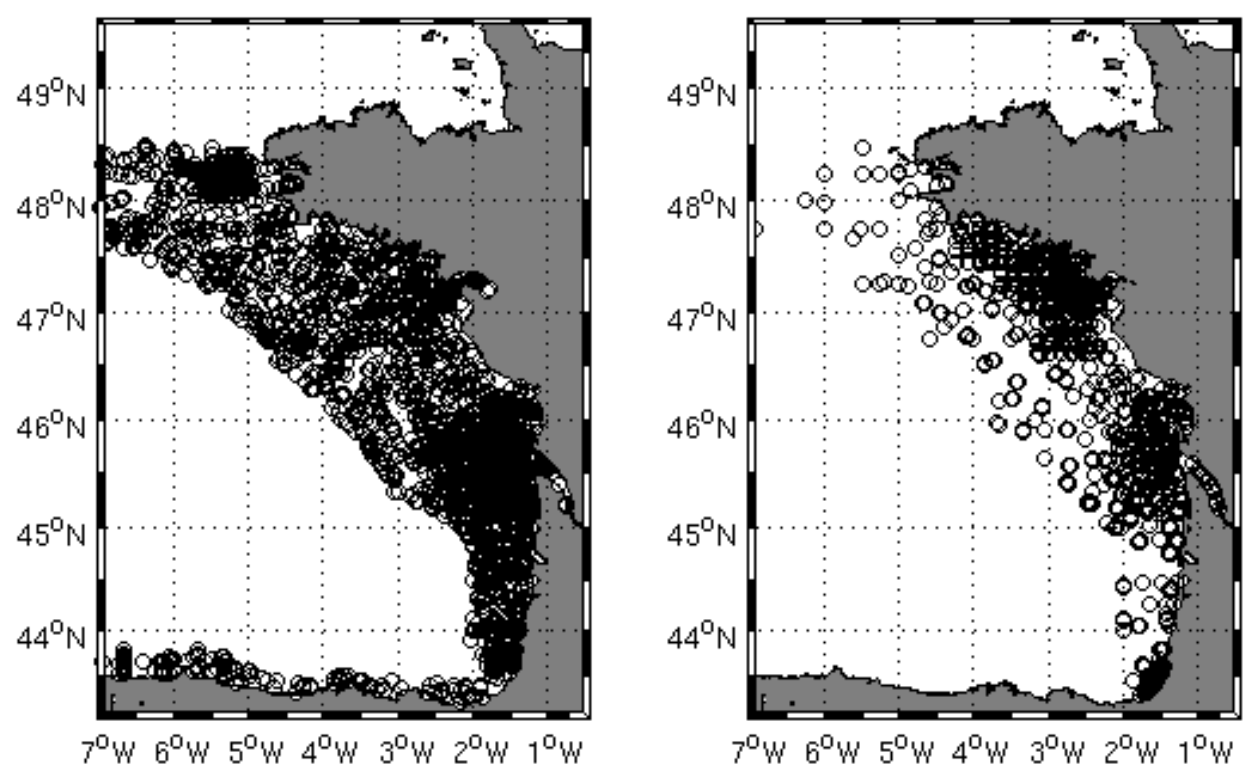

Fig. 6. Spatial distribution of available in-situ observations over the period 1972-2008 for model skill assessment. CTD casts (left panel) and water sampling (right panel) for chlorophyll-a analysis. 

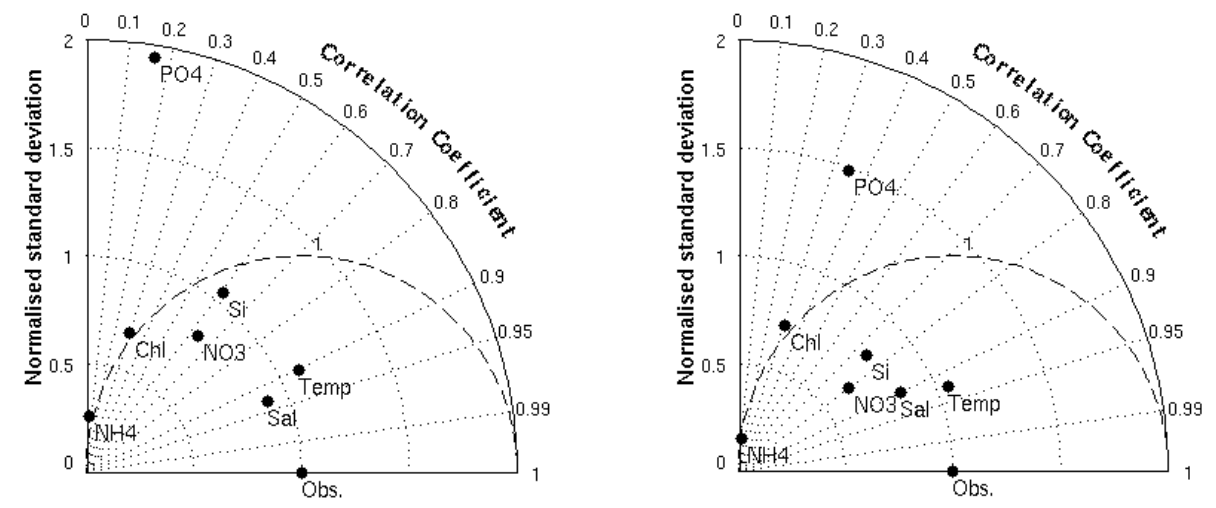

Fig. 7. Taylor diagram on a set of model variables for (a) the whole water column and (b) for surface $(<5 \mathrm{~m})$ over the shelf area of the Bay of Biscay. Model/data comparison is made on all in-situ data available over the hindcast period (see text for details). Three pattern statistics are synthesised on the diagram: (i) the radial distance from the origin is proportional to the ratio of standard deviation between the model and data fields, (ii) the azimuthal position indicates the correlation coefficient, and (iii) the distance between the variable position and 'Obs' indicates the unbiased RMS difference. To allow for different quantities to be represented on the same diagram, both the standard deviation and RMS are normalised by the standard deviation of the observations for each variable. 


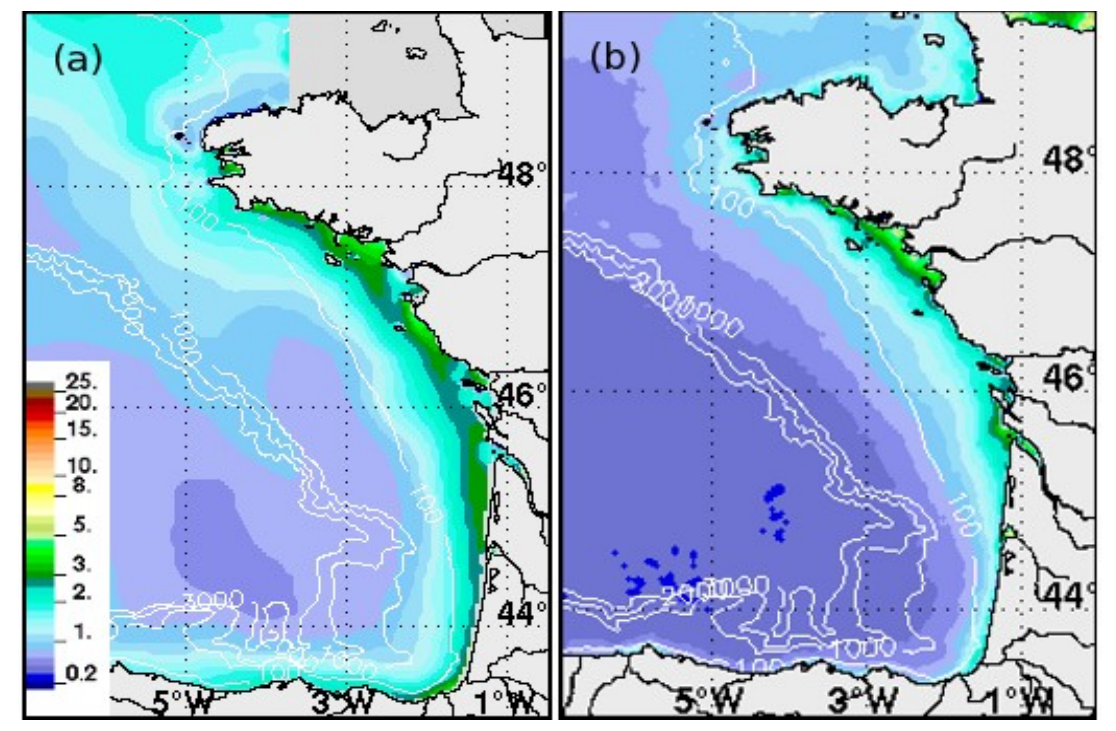

Fig. 8. Annual climatology of surface chlorophyll-a (mgChl.m ${ }^{-3}$ ) from (a) the hindcast and (b) satellite data over the period 1998-2008. The satellite climatology is built from monthly composites of SeaWiFS and MODIS images. Isobaths 100, 1000, 2000 and 3000 are drawn. 


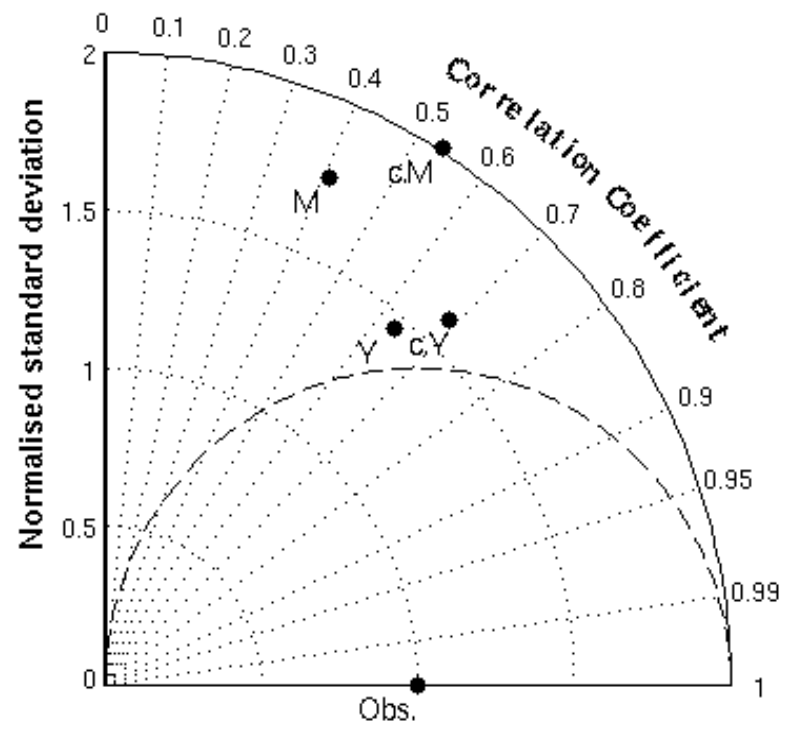

Fig. 9. Taylor diagram comparing monthly of composites of chlorophyll-a from model and satellite data on different timescales over the period 1998-2008. M: All month of all 11 years; c.M: Monthly climatology; Y: All 11 years; c.M: Annual climatology. All grid points are used in the computation (i.e. 12 months $\mathrm{x} 11$ years $\mathrm{x}$ number of grid points in the case of $\mathrm{M}$ ). See Fig.6 for diagram interpretation. 

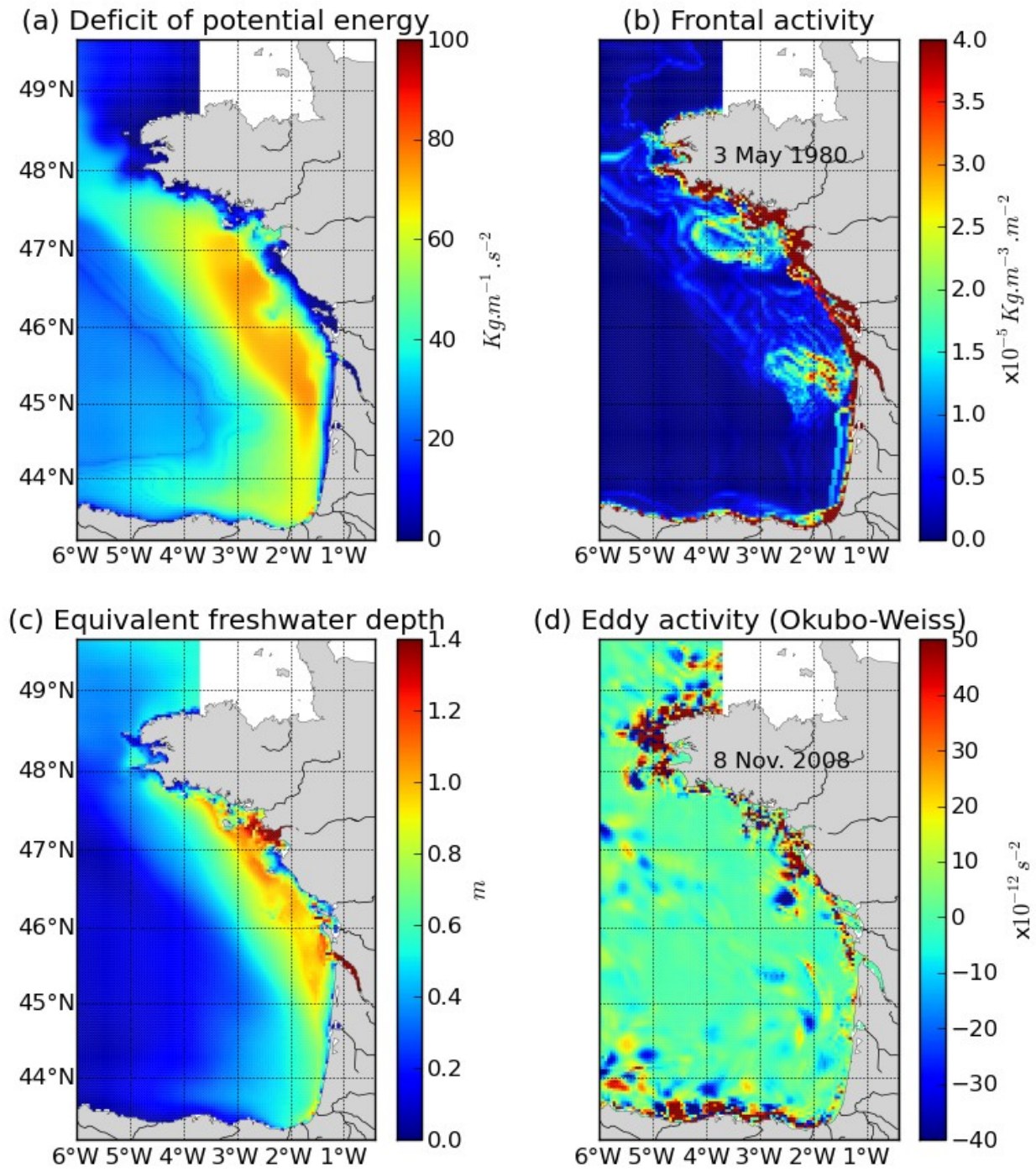

Fig. 10. Annual climatology of the (a) deficit of potential energy $\left(\mathrm{kg} \cdot \mathrm{m}^{-1} \cdot \mathrm{s}^{-2}\right)$ and (c) equivalent depth of freshwater (m), and snapshots of (b) the frontal index (kg.m ${ }^{3} \cdot \mathrm{m}^{-2}$ ) from the maximum vertical gradient of density and of (d) the eddy index from Okubo-Weiss $\left(\mathrm{x} 10^{-12} \cdot \mathrm{s}^{-2}\right)$ criteria. 


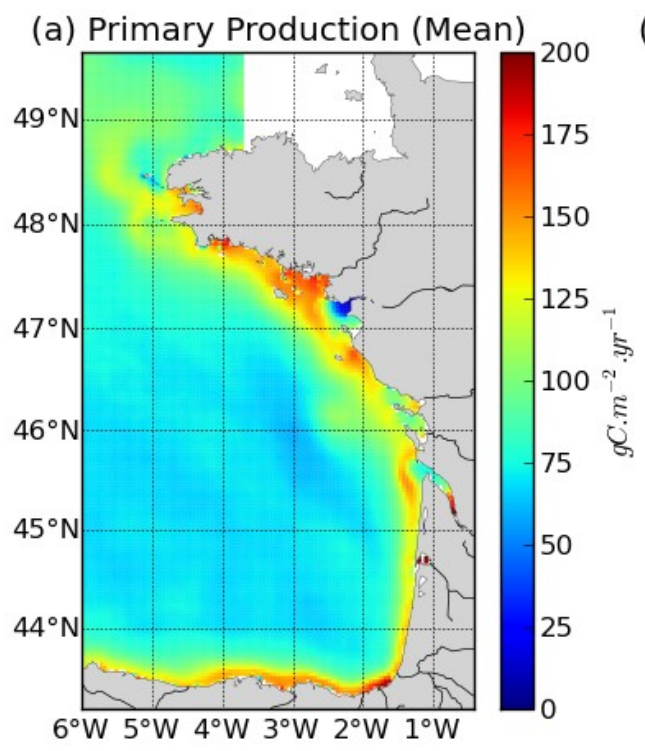

(b) Primary Production (St. dev.)

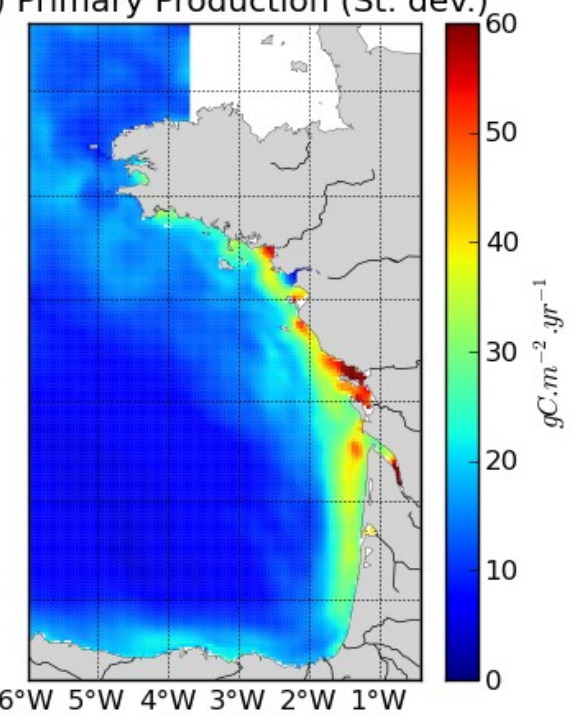

Fig. 11. Integrated annual primary production $\left(g C \cdot \mathrm{m}^{-2} \cdot \mathrm{yr}^{-1}\right)$. (a) Climatology over the hindcast period and (b) associated standard deviation, calculated from annual means of each year. 


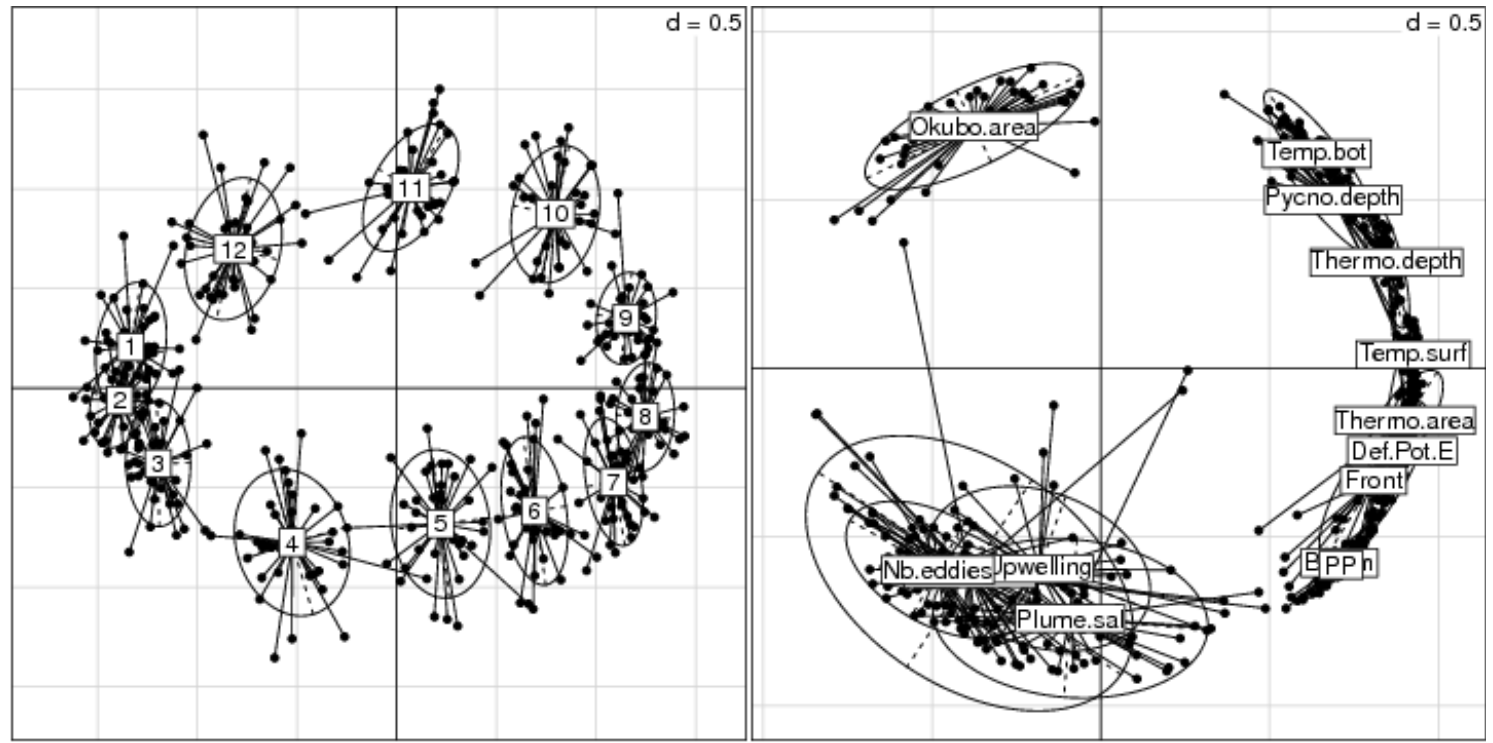

Fig. 12. Seasonal pattern : representation of the mean months (left) and indices (correlation circle: right) in the MFA subspace of the 2 first principal axes, representing $84,3 \%$ of the variability. Each point represents a particular year. Only selected indices of Table 3 are plotted for clarity. 

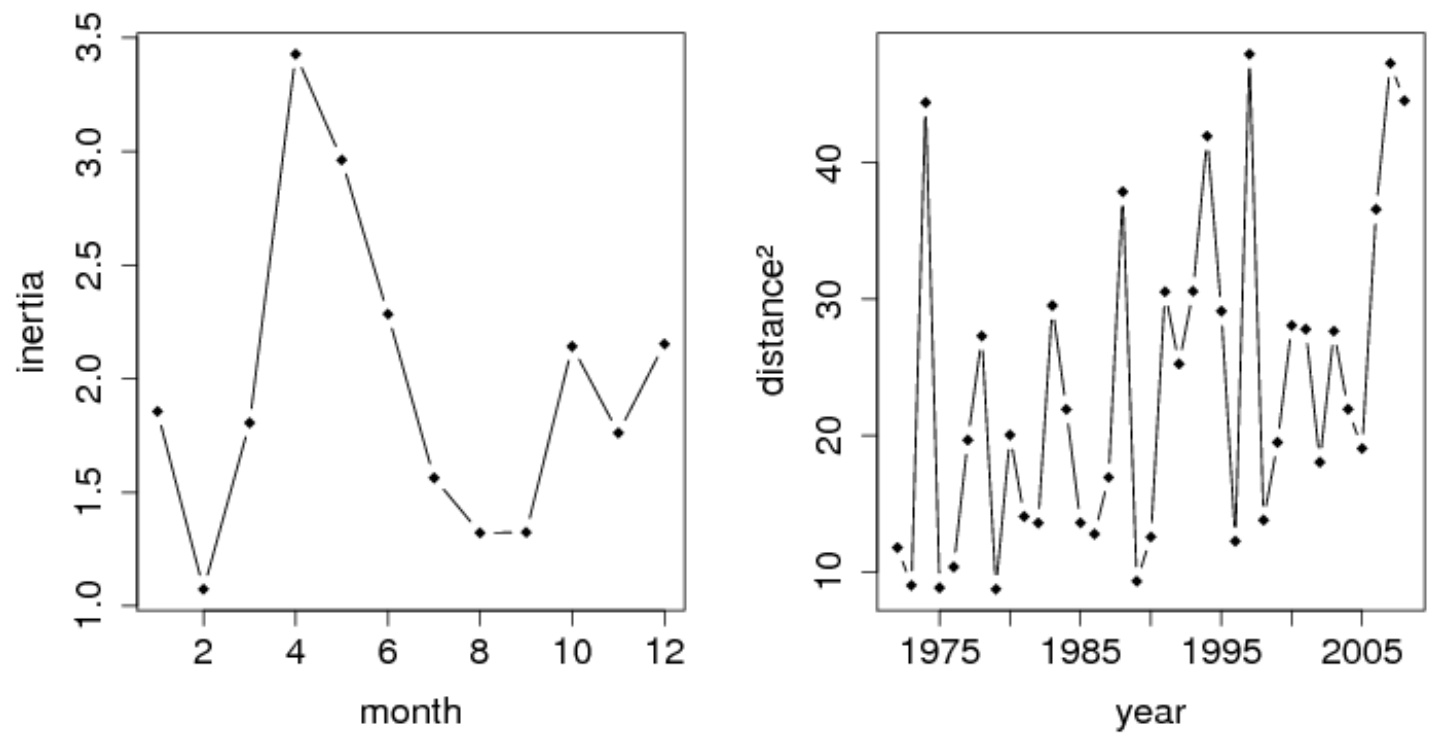

Fig. 13. Variability across years: inertia for each month (left) and distance to the mean seasonal pattern for each year (right) over the Bay of Biscay shelf, as derived from the MFA. 
(a) Surface Temperature

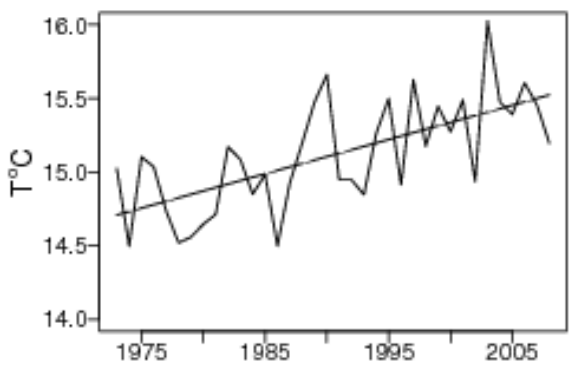

(c) Depth of thermocline

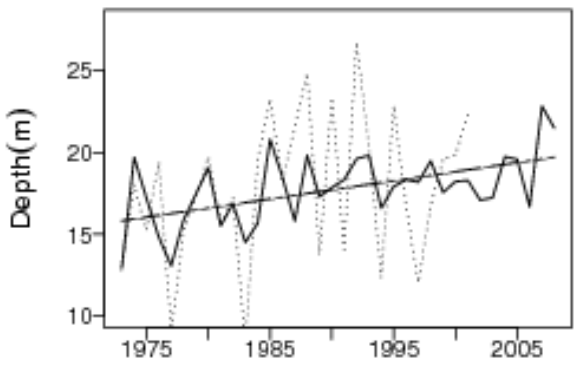

(e) Concentration in chlorophyll

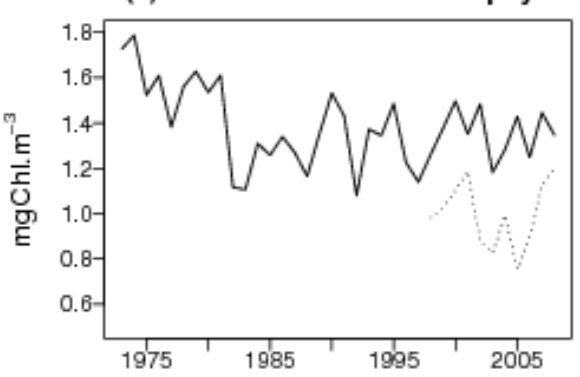

(b) Plume area from EFD

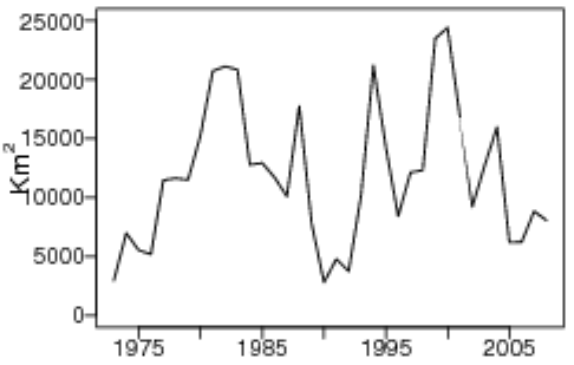

(d) Deficit in potential energy

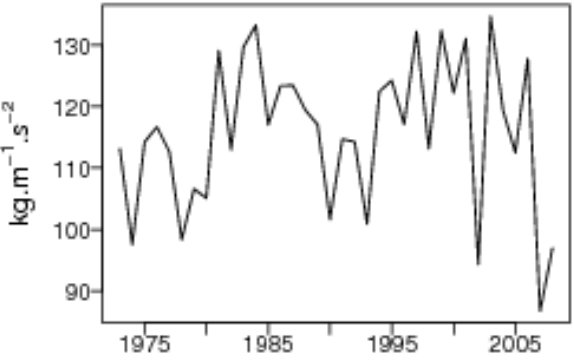

(f) Primary production

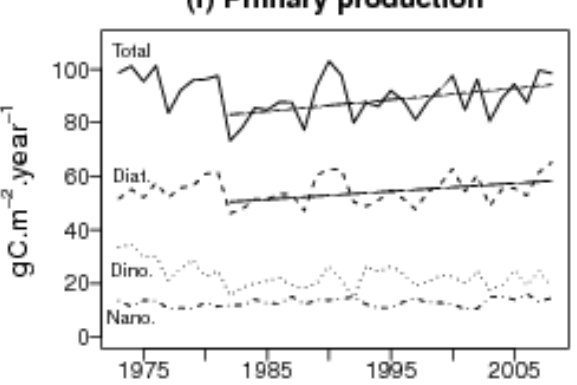

Fig. 14. Time-series of model annual means for (a) surface temperature, (b) plume area, (c) depth of thermocline (with unbiased Bobyclim comparison, see text, dotted line), (d) deficit of potential energy, (e) surface concentration in chlorophyll (with satellite derived chlorophyll-a, dotted line) and (f) integrated primary production for all phytoplankton compartments. Indices are averaged by year over the Bay of Biscay shelf, except for stratification indices (c,d) for which it is averaged for the summer season (months 7, 8 and 9) between $46^{\circ} \mathrm{N}$ and $48^{\circ} \mathrm{N}$ and the 50 and $150 \mathrm{~m}$ isobath. Regression slope is added when significant $(\mathrm{p}<0.05)$. 